\title{
Strong winds in a coupled wave-atmosphere model during a North Atlantic storm event: evaluation against observations
}

\author{
Pineau-Guillou Lucia ${ }^{1}$, Ardhuin Fabrice ${ }^{2}$, Bouin M.-N. ${ }^{1,3}$, Redelsperger Jean-Luc ${ }^{2}$, \\ Chapron Bertrand ${ }^{1}$, Bidlot J.R. ${ }^{4}$, Quilfen Yves ${ }^{1}$
}

${ }^{1}$ Ifremer, CNRS, IRD; UBO /Laboratoire d'Océanographie Physique et Spatiale (LOPS), UMR 6523, IUEM; Plouzané ,France

${ }^{2}$ CNRS, Ifremer, IRD; UBO /Laboratoire d'Océanographie Physique et Spatiale (LOPS), UMR 6523,

IUEM; Plouzané ,France

${ }^{3}$ CNRM, UMR 3589; Météo-France \& CNRS; Toulouse ,France

${ }^{4}$ European Centre for Medium-range Weather Forecasts; Reading ,UK

\begin{abstract}
:
Strong winds may be biased in atmospheric models. Here the ECMWF coupled wave-atmosphere model is used (1) to evaluate strong winds against observations, (2) to test how alternative wind stress parameterizations could lead to a more accurate model. For the period of storms Kaat and Lilli (23 to 27 January 2014), we compared simulated winds with in-situ - moored buoys and platforms - and satellite observations available from the North Atlantic. Five wind stress parameterizations were evaluated. The first result is that moderate simulated winds $(5-20 \mathrm{~m} \mathrm{~s}-1)$ match with all observations. However, for strong winds (above $20 \mathrm{~m} \mathrm{~s}-1$ ), mean differences appear, as much as $-7 \mathrm{~m} \mathrm{~s}-1$ at $30 \mathrm{~m} \mathrm{~s}-1$. Significant differences also exist between observations, with buoys and ASCAT-KNMI generally showing lower wind speeds than the platforms and other remote sensing data used in this study (AMSR2, ASCATRSS, WindSat, SMOS and JASON-2). It is difficult to conclude which dataset should be used as a reference. Even so, buoy and ASCAT-KNMI winds are likely to underestimate the real wind speed. The second result is that common wave-age dependent parameterizations produce unrealistic drags and are not appropriate for coupling, whereas a newly empirically-adjusted Charnock parameterization leads to higher winds compared to the default ECMWF parameterization. This proposed new parameterization may lead to more accurate results in an operational context.
\end{abstract}

Keywords : air-sea exchanges, the North East Atlantic, winds, IFS, sea state, roughness length, drag coefficient, wind stress 


\section{Introduction}

Winds over the ocean generate waves, storm surges and are a dominant source in driving the ocean circulation, including western boundary currents, upwellings and coastal circulations. They are also a major contributor to surface air-sea turbulent fluxes (heat, moisture and momentum). In ocean and wave modelling, winds are generally taken as a forcing field provided by an atmospheric model (e.g. operational analyses or reanalysis). Several studies suggest that strong winds may be systematically underestimated by atmospheric models, with a consequent underestimation in storm surges and wave models. Rascle et al. (2013) observed a bias between the wave model WAVEWATCH III ${ }^{\circledR}$ and observations depending on the winds fields, 5\% for the Climate Forecast System Reanalysis (CFSR) (Saha et al., 2010) and 15\% for the European Centre for Medium-range Weather Forecasts (ECMWF) operational analyses. Hanafin et al. (2012) and Stopa and Cheung (2014) showed that large wave heights were underestimated when forcing the simulations with ECMWF operational analyses or ERA-Interim reanalysis (Dee et al., 2011). So far, it is not clear whether the strong negative bias obtained in wave simulations is caused by underestimated wind speed, or inaccurate 
stress formulation, or imprecise wave growth and dissipation parameterization at high wind speeds. The possible underestimation of high winds in atmospheric models is probably not the only explanation for wave underestimation. Parameterization of wind stress could also be another reason. Indeed, for a given wind field aloft, lower drag coefficient $C_{d}$ will result in lower friction velocity and, as a feedback, will yield higher surface wind.

For atmospheric modelling, obtaining reliable atmosphere to ocean momentum fluxes is crucial. It encompasses a very broad field of time scales and atmospheric phenomena, from the instantaneous forecast of fine-scale events (nowcast) to global climate runs over several decades (Shimura et al., 2017). In atmospheric models, various parameterizations for the magnitude of drag coefficient $C_{d}$ produce wind speeds above $10 \mathrm{~m} \mathrm{~s}^{-1}$ with $10 \%$ or more relative discrepancies between data sets (Rascle and Ardhuin, 2013). In ocean models, various $C_{d}$ parameterizations can modify storm surges amplitude by up to 20\% (Mastenbroek et al., 1993, Muller et al., 2014).

The ECMWF Integrated Forecasting System (IFS) is unique in using a coupled system between its atmospheric model and the wave model ECWAM operationally, thus providing a dynamic prediction of the drag coefficient as a function of the sea state. This $C_{d}$ representation was developed by Janssen (1991) to reproduce the behaviour of the coupled waveatmospheric boundary layer model of Janssen (1986). This parameterization was generally found to provide more accurate weather forecasts (Janssen, 2004). Nevertheless, there are few reliable observations at strong wind speeds for comparisons. Several recent field experiments produced estimations of $C_{d}$, based on direct in situ measurements (Black et al., 2007; Edson et al., 2013) or indirect ones (e.g. Powell et al., 2003; Holthuijsen et al., 2012), as well as laboratory tank measurements (e.g. Donelan et al., 2004; Jarosz et al., 2007; Takagaki et al., 
2012). At wind speeds above $20 \mathrm{~m} \mathrm{~s}^{-1}$, reported $C_{d}$ observations are significantly lower than those given by the ECMWF parameterization.

The present work started from the possible link between a probable underestimation of strong winds in some (or most) atmospheric models and high values of $C_{d}$ used in their boundary layer parameterizations. The objective of the present paper, based on a numerical simulation of the case study of the two extratropical storms Kaat and Lilli which crossed the North Atlantic in January 2014, is twofold: how strong are the biases for high wind speeds in atmospheric models, and can they be corrected by changing Cd parameterizations? For this we first evaluated the strong surface wind speeds obtained using the default parameterization used operationally in the IFS by comparing them with observations. We then tested several alternative parameterizations (including a newly developed parameterization) to attempt to reduce the discrepancies between the modelled and observed strong winds. The first part of this paper describes the Kaat and Lilli storm events. In the following part, we describe the coupled wave-atmosphere model, as well as the different sources of wind observations: satellite data, buoys and platforms. Then, we focus on the comparisons between simulated winds and observations. Finally, we analyse the impact of several parameterizations including a newly developed one - on the atmosphere.

\section{Case study: storm description}

In the following paragraphs, we describe the selection criteria for the case study, the synoptic situation and the storm tracks.

\subsection{Event selection}

The events that are the subject of the present study were selected from ERA-Interim (Dee et al., 2011), a global atmospheric reanalysis produced by ECMWF, covering the years 1979 to 
present time. The horizontal resolution is about $80 \mathrm{~km}$, forecast outputs are every 3 hours, and analyses every 6 hours. To take advantage of recent satellite wind data, we restricted our selection from 2005 to 2015 and to the North East Atlantic only ( $30^{\circ} \mathrm{W}$ to $10^{\circ} \mathrm{E}$ and $30^{\circ} \mathrm{N}$ to $65^{\circ} \mathrm{N}$, see geographical extension Figure 3 ). The 10 most energetic events were selected taking into account two criteria: maximum $10 \mathrm{~m}$ wind speed higher than $32 \mathrm{~m} \mathrm{~s}^{-1}$ and minimum Mean Sea Level (MSL) pressure lower than 975 hPa (Table 1). Wind, MSL pressure and significant wave height (Hs hereafter) come from ERA-Interim analyses, whereas wind gust and precipitation come from ERA-Interim forecasts. The storm names were taken from the Germany's National Meteorological Service (DWD) nomenclature. No name is attributed when the storm is too far from Europe, and two names are mentioned when a primary system is followed by a second one.

Among these 10 events, a particular case was selected. We chose the event with the strongest winds, where satellite remote sensing data was available (e.g. AMSR2 radiometers data have been available only since 2012). The storms Kaat and Lilli of 25 January 2014, classified $5^{\text {th }}$, were the best candidates. The next part presents an overview of these storms.

\subsection{Synoptic situation}

Synoptic charts from DWD show the evolution of the situation (Figure 1). From 23 to 26 January, Kaat crossed the North Atlantic, moving from the East coast of Canada to Iceland, whereas Lilli was generated from a secondary cyclogenesis on 25 January. It started in the middle of the North Atlantic and moved on a more southerly path towards Northern Europe, and reached Scotland on the 26 January. 


\subsection{Storm tracks}

Hoskins and Hodges (2002) analysed the winter storm track organization and behaviour in the Northern hemisphere, from a climatological point of view. The storm tracks in the North Atlantic lower troposphere were classified along two main common paths (cf. the black dotted lines in Figure 2). The first path starts from the east coast of North America, then crosses the North Atlantic, moving in a north-easterly direction, reaching Iceland and continuing along the east coast of Greenland to finally dissipate near Svalbard. The second path is located further south; it starts from the middle of the North Atlantic, and moves in a north-easterly direction, towards the northern part of Europe ending up south of Finland.

Kaat and Lilli storm tracks (cf. the red/blue lines in Figure 2) were computed from the ERAInterim database, following the method elaborated by Hoskins and Hodges (2002). These tracks follow the typical trajectories described above.

Kaat lasted 9 days from 19 to 27 January 2014, including 4 days over the Atlantic which is a typical crossing time. The system appeared on 19 January in land in North Canada, and was probably caused by mountainous cyclogenesis. It then moved south-easterly to reach the Atlantic on 21 January 2014. Crossing the ocean along a north-easterly path, it passed Iceland on the 25, and finally dissipated along the Greenland coast on the 27 January.

Lilli followed on Kaat, as a secondary system generated on 25 January, in the middle of the North Atlantic. This system moved in a north-easterly direction, reaching an area to the North of Ireland on the 26 January. Then Lilli changed direction, moving south-easterly, and reaching Ireland on the 28 and finally dissipating over Great Britain on the 29 January. According to ERA-Interim, this secondary system was more intense than Kaat, with maximum winds speeds reaching $34.1 \mathrm{~m} \mathrm{~s}^{-1}$, instead of $27.7 \mathrm{~m} \mathrm{~s}^{-1}$. 


\section{Model and observations}

In the following paragraphs, we describe the coupled wave-atmosphere model and the observations used in this study.

\subsection{Coupled wave-atmosphere model}

\subsubsection{Configuration description}

We used the Integrated Forecasting System (IFS) CY41R1 cycle (ECMWF, 2015a), with a TL1279 Gaussian grid corresponding to a spatial resolution around $16 \mathrm{~km}$, and 137 vertical levels. The IFS includes the spectral wave model ECWAM (ECMWF WAve Model, ECMWF, 2015b), which has been coupled within IFS since 1998. To explicitly take into account the wave impact on the atmosphere boundary layer, the Charnock parameter, which defines the roughness length $Z_{\text {owave }}$ (see Eq. (5) and (6)) is exchanged each time step from ECWAM to IFS, whereas IFS produces neutral wind speeds at $10 \mathrm{~m}$ height that are used to force the wave model. The ECWAM uses a coarser horizontal resolution than IFS at around $28 \mathrm{~km}$, with 36 directions and 36 frequencies logarithmically spaced, with starting frequency $0.035 \mathrm{~Hz}$ and an increment of 1.1 .

Hourly output fields include the Charnock parameter, drag coefficient, wind stress, wind speed, and are extracted on a $0.125^{\circ}$ resolution grid over the North East Atlantic. Five days were simulated from 23 January 0000 UTC to 28 January 0000 UTC. In order to keep a similar representation of the atmosphere throughout the whole simulation period, the simulation was restarted from the operational analysis each day at midnight. The simulations presented here do not assimilate data (forecast mode experiment). Initial conditions come from the ECMWF operational analysis, obtained with data assimilation. 
The strong correlation between our 24 hour simulations and the corresponding operational analyses for wind (coefficient $\mathrm{r}$ of 0.94 ) and the $500 \mathrm{hPa}$ geopotential (coefficient $\mathrm{r}$ of 0.99 ) show that the storm is well simulated by the model. To prevent a possible influence of the analysis on the adjustment period over the first few hours of every 24-h simulation, only the time range between 3 and 26 hours after each run start was kept for this study.

\subsubsection{Wind stress representation}

The wind stress $\tau$ is proportional to the square of the friction velocity $u_{*}$ in the surface layer, which corresponds to the average of the wind fluctuations:

$$
\tau=-\rho_{\text {air }} \overline{u^{\prime} w^{\prime}}=\rho_{\text {air }} u_{*}^{2},
$$

where $\rho_{\text {air }}$ is the air density, $u^{\prime}, w^{\prime}$ are the horizontal and vertical wind turbulent fluctuations. Turbulent stress - and wind friction velocity - can be considered as independent of height in the surface boundary layer. Because the space and time resolution of the atmospheric models do not allow an explicit representation of the turbulent fluctuations, the turbulent fluxes, including the wind stress, are represented by bulk formulas. These formulas assume that the stress and the wind are aligned and relate the stress and the mean wind speed at a given height, generally $10 \mathrm{~m}$ above sea surface, through a drag coefficient $C_{d}$ :

$$
\tau=\rho_{\text {air }} C_{d} U_{10}^{2},
$$

where $C_{d}$ and $U_{10}$ are the drag coefficient and the wind speed at $10 \mathrm{~m}$ above the surface, respectively. In neutral conditions, the drag coefficient can be expressed as:

$$
C_{d}=\frac{\kappa^{2}}{\left[\log \left(\frac{10}{z_{0}}\right)\right]^{2}},
$$

where $z_{0}$ is the roughness length, and $\kappa$ is the von Kármán's constant (0.4). Eq. (2) and (3) link the roughness length to the wind stress and to the wind profile. At very light winds, the 
roughness $z_{\text {ovisc }}$ is known to depend on the viscous properties of the flow, whereas at stronger winds, the roughness $Z_{\text {owave }}$ is associated to an overall form drag of the wave field. A common parameterization of the roughness $Z_{0 \text { wave }}$ was given by Charnock (1955), and depends on the surface waves through the friction velocity $u_{*}$. This leads to total roughness:

$$
z_{0}=z_{\text {ovisc }}+z_{\text {owave }}=\frac{0.11 v}{u_{*}}+\alpha \frac{u_{*}^{2}}{g},
$$

where $v$ is the kinematic viscosity, $g$ is the mean gravitational acceleration and $\alpha$ is known as the Charnock's parameter. $\alpha$ can be constant or related explicitly to the wave parameters, in particular the wave age, using different parameterizations (e.g Oost et al., 2002; Drennan et al., 2003).

Janssen (1991) parameterized the quasi-linear wave growth effect as a modification of the wind profile giving way to an effective larger roughness length $\mathrm{z}_{0 \text { wave, }}$ expressed as a function of the wave-induced stress $\tau_{w}$,

$$
z_{0 \text { wave }}=\frac{z_{1}}{\sqrt{1-\frac{\tau_{w}}{\tau}}},
$$

The reference roughness length $z_{1}$ is:

$$
z_{1}=\alpha_{1} \frac{u_{*}^{2}}{g}
$$

with $\alpha_{1}=0.006$. This value of $\alpha_{1}$ has been fixed, so that for old sea, the associated roughness $Z_{\text {owave }}$ (Eq. (5)) corresponds to the standard value of Charnock parameter 0.0185 (Wu, 1982). The wave-induced stress $\tau_{w}$ is the momentum flux transferred from the atmosphere to the waves. It can be related to the wind-wave growth parameter $\beta$ and the directional wave spectrum $E(f, \theta)$ :

$$
\vec{\tau}_{w}=g \int_{0}^{\infty} \vec{k} \int_{0}^{2 \pi} \beta(f, \theta) E(f, \theta) /(2 \pi f) d f d \theta
$$


where $k$ is the wavenumber, $\theta$ the direction and $f$ the relative wave frequency (Janssen, 2004). The wave-growth parameter is expressed as $\beta=\left(\beta_{m} / \kappa^{2}\right) \mu \ln ^{4}(\mu), \mu \leqslant 1$, where $\kappa$ is the von Kármán's constant, $\beta_{\mathrm{m}}$ a constant (1.2), and $\mu$ the dimensionless critical height (ECMWF, 2015b).

The stress $\tau_{w}$, and thus the roughness $z_{0_{w} \text { ave }}$, is highly sensitive to the high frequency content of the wave spectrum, which is in itself highly sensitive to the choice of wave generation and dissipation parameterizations (e.g. Rascle and Ardhuin 2013). In ECWAM, the wave spectrum $E(f, \theta)$ high-frequency tail is diagnostically forced to $E(f, \theta)\left(f_{t} / f\right)^{5}$ for $f>f_{t}$ with $f_{t}=2.5 f_{\text {windsea }}$ and $f_{\text {windsea }}$ the mean frequency of the modelled wind sea (part of the full spectrum corresponding to the wind sea only, and defined where the input source term $S_{\text {in }}$ is positive).

\subsection{Wind measurements}

In this part, we describe the wind observations used to assess the simulated wind speed in our case study.

\subsubsection{General description}

We took advantage of winds both from in situ measurements - buoys and platforms - and remote sensing measurements - scatterometers (ASCAT), passive microwave radiometers (AMSR2, SMOS), passive polarimetric radiometers (WindSat) and altimeters (JASON-2). Some of these data are assimilated in ECMWF operational system, but not assimilated in our simulations. In spite of this, they influence results because initial conditions are taken from operational analyses. The main characteristics of satellite data used in this study are presented in Table 2.

In-situ wind measurements are the most direct measurements of wind speed and are available at high temporal resolution, but restricted to few locations. They represent a smaller surface 
(defined as a footprint) compared to the model grid cell. The buoy footprint is difficult to evaluate, but it can probably represent around one kilometre, depending on the wind speed and on the stratification, whereas the platform footprint is usually larger, depending on the height of the measurement.

Conversely, remote sensing provides wind speeds over a large swath but at sparse temporal resolution, with larger footprints (10 to $30 \mathrm{~km}$ ) than in situ. In recent years, the capability of ocean remote sensing data to characterize high wind speeds, with higher resolution (typically $10 \mathrm{~km}$ in the recent period), has rapidly improved (Chapron et al., 2010; Quilfen et al., 2007; Reul et al., 2017). Their accuracy is theoretically homogeneous and of about $2 \mathrm{~m} \mathrm{~s}^{-1}$, but Chou et al. (2013) reported that ASCAT strong winds (higher than $18 \mathrm{~m} \mathrm{~s}^{-1}$ ) were negative biased about $7 \mathrm{~m} \mathrm{~s}^{-1}$ versus observations. Remote sensing measurements are always indirect and rely on the characteristics of the sea surface: amplitude of short gravity waves, radiometric signature of foam and increased ocean surface with waves to name a few. Geophysical Model Functions (GMFs) are used to transform the measured parameters (radar cross-section and brightness temperature) into wind speeds. They are empirical relationships, generally globally adjusted to in-situ data sets, other satellites products, or atmospheric numerical models outputs. As a result, different training datasets can produce different GMFs. Especially high wind speed regime estimates can then vary between different processing algorithms that start from the same raw satellite data.

All the wind observations used in this study are corrected to correspond to a height of $10 \mathrm{~m}$ above the sea surface. Data from satellites are generally conventionally referred to as neutral winds, whereas data from models and in situ are non neutral. In this study atmosphere stability effects are not taken into account, as they are considered to be second order for 
strong wind situations. Wind speeds on 26 January 2014 obtained from the different satellites and in situ datasets are listed below and presented Figure 3, a to f.

\subsubsection{ASCAT scatterometer}

The Advanced SCATterometer (ASCAT) is a real aperture radar, to enable the estimation of wind speed and direction from backscatter coefficients. It is carried onboard the Meteorological Operational (Metop) polar satellites, launched by the European Space Agency (ESA) and operated by EUMETSAT (EUropean organisation for the exploitation of METeorological SATellites). Metop-A was launched in 2006, Metop-B in 2012.

ASCAT wind products used in this study are provided by KNMI (Royal Netherlands Meteorological Institute) and RSS (Remote Sensing Systems). The ASCAT-KNMI is a Level 2 swath product, with a 12.5-km spatial resolution, using Metop-A and Metop-B data. The ASCAT-RSS version 2.1 is a gridded product, with $0.25^{\circ}$ spatial resolution, based on Metop-A data only. For these two data sets, rain contaminated data are discarded depending on the rain flags.

The comparisons between winds from ASCAT-KNMI and ASCAT-RSS on 26 January 2014 for Metop-A (Figure 3 a-b) show that RSS high winds are stronger than KNMI, clearly related to different retrieval algorithms. The GMF used by RSS is calibrated on SFMR winds (Stepped-Frequency Microwave Radiometer onboard aircrafts), whereas KNMI GMF is calibrated on buoys and ECMWF winds (Verspeek et al., 2012).

Scatterometers have a decreased sensitivity at high winds, leading to difficulties in calibrating the GMF at strong winds and to a possible underestimation of high winds (Quilfen et al., 1999; Bentamy et al., 2008; Sapp et al., 2016).

To note, KNMI ASCAT winds and ECMWF operational winds are not independent: ASCAT wind retrievals rely on ECMWF winds through their "ocean calibration process" (Verspeek et 
al., 2012) and ASCAT winds are assimilated in ECMWF operational analysis (De Chiara et al., 2016). For the assimilation operations, ECMWF recomputes ASCAT winds from the backscatter coefficients, using a procedure very similar to KNMI. The wind speeds obtained are then systematically corrected to avoid a global bias between ASCAT and the model, prior to data assimilation.

\subsubsection{AMSR2 radiometer}

The Advanced Microwave Sounding Radiometer 2 (AMSR2) is a passive microwave radiometer, enabling estimation of wind speeds from brightness temperature of the oceans. It is operated onboard the GCOM-W1 satellite since 2012.

AMSR2 winds are provided by SOLab (Satellite Oceanography Laboratory, Russian State Hydrometeorological University). The wind product used in this study is Level 2, ungridded, with a spatial resolution of $10 \mathrm{~km}$. Low microwave frequency winds were preferred, as high microwave frequency AMSR2 algorithm can significantly underestimate high winds and is more likely contaminated by atmospheric liquid water content. Comparisons (Zabolotskikh et al., 2014) show that the AMSR2 wind products obtained using the low-frequency based algorithm exhibit very strong correlation with platform winds for high wind speeds. The data we used were filtered for outliers and interpolated on a regular grid of $0.1^{\circ} \mathrm{x} 0.1^{\circ}$ (Figure $3 \mathrm{c}$ ). Areas without data near the center of the storm are due to rain masking. These areas are reduced to a minimum thanks to efficient processing of rain effects on brightness temperature measurements (Zabolotskikh et al., 2013, 2014).

AMSR2 winds are not assimilated in ECMWF numerical weather prediction system. However, the radiances are directly assimilated (Kazumori et al., 2015). 


\subsubsection{WindSat radiometer}

WindSat is a multi-frequency polarimetric microwave radiometer (Gaiser et al., 2004). It provides estimates of the ocean surface wind vector from brightness temperatures. It has operated since 2003 onboard the Coriolis satellite.

WindSat data are processed and distributed by RSS. Data are inter-calibrated with the other microwave radiometers. As for AMSR2, low microwave frequency 10-m winds were preferred to high-frequency winds. Even if their effective resolution is lower $(25 \mathrm{x} 38 \mathrm{~km}$ instead of $16 \times 27 \mathrm{~km}$ ), they are less affected by the atmosphere and rain (Meissner and Wentz, 2009). The data set consists of a daily product v7.0.1. on a $0.25^{\circ}$ grid (Figure 3d).

WindSat data are not assimilated in ECMWF numerical weather prediction system; these data and simulated winds are thus totally independent from each other.

\subsubsection{SMOS radiometer}

MIRAS (Microwave Imaging Radiometer by Aperture Synthesis) is a L-band radiometer, whose primary goal was to estimate soil moisture and ocean surface salinity, in the framework of ESA's Soil Moisture Ocean Salinity (SMOS) mission. However, in addition, the observed sensitivity of the excess emissivity at L-band can been interpreted in terms of high wind speed (Reul et al., 2012; Reul et al., 2016). This instrument is only marginally affected by rain and clouds, and can provide complementary information about storm structures and intensity. SMOS wind data are produced and archived at CERSAT (Ifremer). The Level 2 (gridded) 15 $\mathrm{km}$ wind data product was used here. SMOS winds are not assimilated in ECMWF numerical weather prediction system. 


\subsubsection{JASON-2 altimeter}

The Jason-2 altimeter operates at two frequencies $(13.6 \mathrm{GHz}$ in the $\mathrm{Ku}$ band, $5.3 \mathrm{GHz}$ in the $\mathrm{C}$ band) to determine ionospheric electron content, which affects the radar signal path delay. This dual-frequency capability can be used to mitigate contamination of the normalized radar cross section measurements, NRCS, by rain (Quilfen et al., 2006). The NRCS data from the Geophysical Data Records (GDR) are processed at the Aviso center in Toulouse under the responsibility of the Centre National d'Etudes Spatiales (CNES) and the National Aeronautics and Space Administration (NASA). The NRCS measurements do not show systematic saturation at high wind speed up and above hurricane force (Quilfen et al., 2006; Hanafin et al., 2012). This sensitivity enables derivation of altimeter high wind speed estimates (Figure 3e) using a GMF tailored with radiometer measurements (Quilfen et al., 2011). JASON-2 winds are not assimilated in ECMWF numerical weather prediction system.

\subsubsection{Buoys}

Buoy networks (Figure 3a) are mainly deployed by meteorological offices. In the North East Atlantic, data providers are the UK Met Office, Irish Marine Institute, Meteo-France, and Puertos del Estado. Buoy data come from the Wave Forecast Verification Project managed by ECMWF for JCOMM (the Joint Technical Commission for Oceanography and Marine Meteorology). A brief quality control was carried out on wind observations, based on a visual check. We kept all the buoys, and we adjusted the wind data from measurement height (usually from 2 to $4 \mathrm{~m}$ ) to $10 \mathrm{~m}$, based on a logarithmic law. A total of 20 buoys is available. Buoy wind measurements are likely affected by sea state and buoy motion, and so could potentially underestimate high wind speeds (Zeng and Brown, 1998; Zabolotskikh et al., 2014). The wind speed could further be reduced because of sheltering effects by waves (Skey et al., 1995). 
Buoy winds are assimilated in ECMWF forecasting system.

\subsubsection{Platforms}

Platforms are all located in the North Sea (Figure 3a), and are deployed mainly by oil and gas private companies. Data come from the GTS (Global Telecommunication System) and Norwegian Meteorological Institute. Data were selected using the same method as buoys. The brief quality control leaded to the invalidation of 7 platforms among 67. Platforms wind data are generally reduced to $10 \mathrm{~m}$, with methods depending on data providers and about which precise information is difficult to obtain. For Met Norway, wind speed $U$ at height $\mathrm{z}$, is reduced to $10 \mathrm{~m}$ using a wind power law expressed as:

$$
U_{10}=U\left(\frac{10}{Z}\right)^{0.13},
$$

This formulation, with the exponent empirically determined, is often used when no information about stability or surface roughness is available (Furevik et al., 2012).

Multiple wind speed data coming from platforms located in the same grid cell of the IFS model were averaged to obtain one value per model grid cell, to enable a more coherent comparison. Finally, 59 averaged stations were available.

Wind sensors on platforms are usually located higher than on buoys (e.g. more than $100 \mathrm{~m}$ for some platforms in North Sea). While Zabolotskikh et al. (2014) consider that platform measurements are more accurate than buoy measurements for high winds, transforming wind measurements at more than $100 \mathrm{~m}$ to 10 -m wind speed using empirical formulas like Eq. (8) is an additional source of uncertainty.

GTS platforms winds are presented to ECMWF data assimilation system. 


\section{Comparison between simulated winds and observations}

In this part, we assess the wind speeds obtained in the Kaat-Lilli simulation using the default ECMWF parameterization by comparing them with observations. Collocations were made with all available observations as described in section 3 during the five days of simulation (23 to 27 January 2014) on the North East Atlantic $\left(30^{\circ} \mathrm{W} 10^{\circ} \mathrm{E} 30^{\circ} \mathrm{N} 65^{\circ} \mathrm{N}\right.$, see geographical extension Figure 3). For in-situ observations (buoys and platforms), temporal resolution is the same as the model (1 hour) and all the data are used for comparison. For remote sensing, data are considered collocated and used for the comparison if the time difference between model and observations is less than 15 minutes. The model, whose default resolution is $16 \mathrm{~km}$, was extracted on a $0.125^{\circ}$ grid, so the maximum distance between observations and model (depending on the grid resolution of the observations, see Table 2) is around $6 \mathrm{~km}$. The number of correlated points between simulated and observed winds depends on each instrument: it ranges from 2,389 points for buoys up to 367,032 for ASCAT-KNMI (Table 2). The correlation coefficients (r), for the wind speed range $0-40 \mathrm{~m} \mathrm{~s}^{-1}$, range from 0.95 for ASCAT-KNMI to 0.79 for SMOS (Table 3). This lower value for SMOS is due to a noisier signal (Figure 4e). At high wind speeds, simulated winds are consistent throughout the whole range with ASCAT-KNMI winds (Figure 4a) and buoy winds (Figure 4g). In contrast, simulated winds show a negative bias with respect to all other data (Figure 4b,c,d,e,f,h). ASCAT-RSS and WindSat correlations are similar, because they were processed by the same data provider (RSS), using WindSat products as a reference for calibrating ASCAT winds. Note that strong winds from platforms are higher than ECMWF ones, which is not the case for buoy winds. To analyse in greater depth the differences between datasets, we computed biases between ECMWF simulations and observations. 


\subsection{Biases}

Wind biases were computed between ECMWF simulations and observations (Figure 5). We averaged differences between model and observations along the x-axis as well as along the yaxis, every bin of $1 \mathrm{~m} \mathrm{~s}^{-1}$. Note that the curves end at different wind speeds depending on observations. This is partly due to different spatial coverage according to the instruments used (e. g. a buoy or a satellite do not see the same event spatially) and to biases between datasets (e.g. ASCAT-RSS strong winds are higher than KNMI ones, then RSS curve ends after KNMI one). Error bars are not displayed in the figure in order to improve readability, but standard deviations and root mean square errors are given in Appendix B. For very high winds (> $30 \mathrm{~m}$ $\mathrm{s}^{-1}$ ), biases are statistically less relevant, as they are computed with only a few points. Moreover, for this range of wind speed, uncertainties of observations increase dramatically, as there is a lack of high quality measurements. For these reasons, values for this wind speed range are only plotted as points on figures of biases (Figures 5, 6 and 11).

The first result is that for moderate winds $\left(5-20 \mathrm{~m} \mathrm{~s}^{-1}\right)$, the biases are slight $\left( \pm 1\right.$ to $\left.2 \mathrm{~m} \mathrm{~s}^{-1}\right)$ for all observations. This shows that the model agree well with all observations.

The second result is that for winds stronger than $20 \mathrm{~m} \mathrm{~s}^{-1}$, biases are generally negative or close to zero, showing that simulated winds are generally lower than observations. Observations can be divided into two groups: one with small biases, the other one with large. The first group with small biases is composed of ASCAT-KNMI and buoys. The bias between model and buoys is close to zero. This result is not surprising, as buoys are used as one of the reference data used to calibrate the ECMWF model. The bias between ECMWF and ASCATKNMI is also close to zero up to $25 \mathrm{~m} \mathrm{~s}^{-1}$. It then slowly increases with wind speed to reach about $-2 \mathrm{~m} \mathrm{~s}^{-1}$ at $30 \mathrm{~m} \mathrm{~s}^{-1}$. Note that the last binned value with a positive bias must be carefully interpreted, because it represents only a few points with large standard deviations (Figure B1). 
This slight negative bias with ASCAT-KNMI is not at all surprising as ASCAT-KNMI retrievals strongly rely on ECMWF winds for calibration (Verspeek et al., 2012) (see 3.2.2). Moreover, buoys are used to calibrate empirical scatterometer GMFs (Zeng and Brown, 1998) at KNMI. In conclusion for the first group, ECMWF, ASCAT-KNMI and buoy winds all agree well, as indeed, each of the three data source are mutually inter-dependent.

The second group with stronger biases is composed of all the other satellite or in-situ wind products considered in this study (scatterometer from RSS, radiometers, altimeter and platforms). ECMWF high winds are systematically lower than these observations with a significant bias increasing with wind speed. Bias is of about $-4 \mathrm{~m} \mathrm{~s}^{-1}$ at $25 \mathrm{~m} \mathrm{~s}^{-1}$, and reaches $-7 \mathrm{~m} \mathrm{~s}^{-1}$ at $30 \mathrm{~m} \mathrm{~s}^{-1}$. AMSR2, WindSat and SMOS products are all consistent, because of shared sensitivities of the foam-induced brightness temperature to wind speed for these passive microwave wind sensors, but also of dedicated efforts to calibrate and align high wind speeds. Note that AMSR2 and WindSat are also consistent due to the combination of (1) similar retrieval algorithms between AMSR2 and SFMR (2) SFMR data being used as a reference for WindSat GMFs calibration. Strong correlations between platforms and AMSR2 have already been reported (Zabolotskikh et al., 2014). While there is still no full consensus on calibration between data providers, the overall agreement between these remote sensing data sets is encouraging.

\subsection{Discussion}

The estimates of correlations and biases between ECMWF simulations and observations show that there are systematic biases between ECMWF and most datasets derived from observations at high wind speeds. Moreover, biases exist between various datasets.

These results suggest a possible underestimation of ASCAT-KNMI high winds, as already mentioned in previous studies (Chou et al., 2013). It can be associated with a decrease of 
sensitivity of scatterometry instruments at high winds, which make calibration more complicated in this wind range, whereas radiometers show a better sensitivity and no saturation issues at high wind speeds (Quilfen et al., 2007; Reul et al., 2017). ASCAT-RSS high winds are estimated using a different GMF, and are stronger than KNMI ones because wind products are tailored to the radiometer winds. Apparently, this method mitigates the reduced sensitivity of scatterometer measurements.

There is also a significant bias between buoys and platforms at high wind speeds. Buoy winds are lower than platform winds, by about $3 \mathrm{~m} \mathrm{~s}^{-1}$ at $25 \mathrm{~m} \mathrm{~s}^{-1}$. Earlier works mentioned that buoys could underestimate high wind speeds (Zeng and Brown, 1998), because of sea state, buoy motion and sheltering effects. All these differences raise questions on the relevancy of measuring wind at such heights and on the methods used to reduce values to $10 \mathrm{~m}$. Buoys used in this study measure at 2 to $4 \mathrm{~m}$ in height, in a reference frame moving with waves, whereas the height of the sensors on platforms is typically 60 to $150 \mathrm{~m}$. We made similar comparisons between ECMWF simulated winds and platform winds at the height of the sensor (not shown), leading to similar biases showing an underestimation comparable to $10 \mathrm{~m}$ winds. Further work is needed to analyse if wind on platforms is representative of wind around the platform, and if structure effects could generate differences.

In conclusion for strong winds, we found biases between the two groups of data: on one hand ECMWF, buoys and ASCAT-KNMI winds match well, and on the other hand, platforms and other satellite winds also match well but are higher, with biases reaching $-7 \mathrm{~m} \mathrm{~s}^{-1}$ at $30 \mathrm{~m} \mathrm{~s}^{-1}$. Defining the reference for observed winds between these two groups is certainly not evident. There are many assumptions and approximations in models, experiments and data processing. Note that in the first group, the common link is buoys, and is used as a reference for ECMWF model validation and ASCAT-KNMI calibration. Several studies mentioned a possible 
underestimation of buoy winds (Zeng and Brown, 1998). This could cause the first group of data to be biased low.

\subsection{Application to other storms}

In order to have more robust statistics, we applied this method to three other storms. We selected them among the ten more energetic events over period 2005-2015 in the North East Atlantic (Table 1). We chose the events with the strongest winds, where remote sensing data was available. The storms Alexandra, Ulrich and Uwe were the best candidates. Simulations were conducted during 5 days, and wind biases were computed between model and buoys, platforms, ASCAT-KNMI, WindSat and SMOS data. The method was exactly as described previously, except that we use L3 instead of L2 products for ASCAT-KNMI winds. Results on Figure 6 are comparable to the ones obtained for Kaat and Lilli storms, showing the same order of magnitude for the underestimation of high winds. We find the same bias between buoys and platforms, except for Erich storm where buoy and platform winds are coherent.

\section{Sensitivity to wind stress parameterization}

In this part, we examine five alternative wind stress parameterizations (Table 4), including a newly developed one. The objective is to evaluate how high winds could deviate from those derived from ECMWF default parameterization.

\subsection{Alternative wind stress parameterizations}

In the coupled wave-atmosphere model, the effects of waves on the stress is represented by a modification of the Charnock parameter $\alpha$. The operational ECMWF parameterization is used as a reference ([1] in Table 4).

The second parameterization ([2]) uses an adjustment to the Janssen parameterization described as “ST4-TEST471” in WW3DG (2016) and also implemented in ECWAM. It uses 
Eq. (7), as in default ECMWF, but with $\beta$ given by Ardhuin et al. (2010) and $E(f, \theta)$ influenced by a different dissipation term. The main difference consists in the parameterization for the dissipation of waves, based on swell dissipation measurements (Ardhuin et al., 2009) and the saturation-based dissipation of Phillips (1985), that gives excellent results in terms of wave heights and spectral parameters, including a spectral tail that is significantly different from the one produced by the Janssen (1994) parameterizations. Parameterizations in Ardhuin et al. (2010) had spurious jumps in the swell dissipation rate that was corrected in Rascle and Ardhuin (2013), but show very little variability of $C_{d}$ as a function of wave age (Rascle and Ardhuin, 2013). This reduced variability of $C_{d}$ comes from a sheltering coefficient $s_{u}$, set to 1 in Ardhuin et al. (2010), that reduces the wave growth at high frequency. It was introduced to balance the dissipation rate. Using $s_{u}=0.3$ restores some of the $C_{d}$ variability. This setting is described as “TEST471” (WW3DG, 2016). The parameters tested in ECWAM are similar with $\alpha_{1}=0.006$ instead of 0.0095 and $s_{u}=0.4$ instead of 0.3 . Note also that WAVEWATCH III TEST471 imposes a high frequency tail as discussed in section 3.1.

The third parameterization ([3]) uses a Charnock parameter defined from the wave-age. Several studies based on observations of sea state and wind stress, devised to demonstrate a possible sea-state influence on the wind stress, suggested than the Charnock parameter may indeed be expressed as a function of the wave age (Donelan 1982; Komen et al., 1998; Oost et al., 2002; Drennan et al., 2003). Considerations based on dimensional analysis led these authors to propose expressions of the form $\alpha=a \xi^{b}$, where $a$ and $b$ are determined from in situ measurements and $\xi$ is the wave age, $\xi=C_{p} / u *$ where $C_{p}$ is the phase velocity at the peak of the wave spectrum. The parameterization by Oost et al. (2002) used in this study, is based on data from a research platform in the North Sea, with wind speed ranging from 6 to $18 \mathrm{~m} \mathrm{~s}^{-1}$, 


$$
\alpha=50 \xi^{-2.5} .
$$

Drennan et al. (2003) suggested another expression, based on data from field campaigns in the Mediterranean Sea, with winds also lower than $20 \mathrm{~m} \mathrm{~s}^{-1}$,

$$
\alpha=1.7 \xi^{-1.7}
$$

The differences between these two references underline the possible influence of the dataset in each parameterization. Moreover, there are still discussions - and no consensus - on these results, as the strong correlations obtained in the observations could be mainly due to selfcorrelation, $u *$ being part of the two parameters $\alpha$ and $\xi$ (Andreas, 2009).

The fourth parameterization ([4]) is our empirically-adjusted Charnock parameterization. It keeps the Janssen (1991) parameterization in the wave model, but modifies the value of $\alpha$ passed to the atmospheric model. This modification keeps the wave-induced variability but reduces the values of $\alpha$ at high wind speeds to obtain values of the drag coefficient closer to those obtained in situ (Powell et al., 2003; Black et al., 2007; Holthuijsen et al., 2012; Edson et al., 2013). These studies give drag coefficients that potentially saturate for winds above 30 $\mathrm{m} \mathrm{s}^{-1}$. This is still a matter of debate, due to uncertainties in wind and stress measurement at very high winds. We adjusted our parameterization to obtain a maximum $C_{d}$ of $2.510^{-3}$ for wind speed around $30 \mathrm{~m} \mathrm{~s}^{-1}$ (Figure 7), and to keep a lower variability with the sea state. We thus relaxed the Charnock coefficient obtained from default ECMWF towards lower values. This adjusted Charnock is only used for the atmospheric model roughness, but the wave model integration is unchanged. For this, we first tabulated the mean Charnock $(\bar{\alpha}$, see Appendix A) given by default ECMWF every $1 \mathrm{~m} \mathrm{~s}^{-1}$ bin, from the full year 2014 of global IFS simulations. Below $15 \mathrm{~m} \mathrm{~s}^{-1}$ we use:

$$
\alpha_{i}=\bar{\alpha}_{i b}+\beta\left(\alpha_{i}-\bar{\alpha}_{i b}\right)
$$


in which we keep the mean Charnock $\bar{\alpha}_{i b}$, but we reduce the variability through the $\beta$ coefficient, ranging from 0 (no variability) to 1 (keeping all variability). Above $15 \mathrm{~m} \mathrm{~s}^{-1}$, we use:

$$
\alpha_{i}=\alpha_{0}+\beta\left(\alpha_{i}-\bar{\alpha}_{i b}\right)
$$

in which the mean Charnock reduced to the constant $\alpha_{0}$. We further adjusted parameters to have drag values more consistent with in-situ measurements (Figure 7), leading to a threshold of $15 \mathrm{~m} \mathrm{~s}^{-1}, \alpha_{0}=0.02$ and $\beta=0.5$. These parameters could be optimized in future studies.

With this parameterization [4], the Charnock variability decreases by a factor two, and the average values of Charnock parameter are lowered for winds greater than $15 \mathrm{~m} \mathrm{~s}^{-1}$ (Figure 8ab). This leads to maximum Charnock values of about 0.06 instead of 0.12 , and an average value of about 0.02 instead of 0.04 at $25 \mathrm{~m} \mathrm{~s}^{-1}$. As a consequence, this parameterization reduces the drag coefficient, the average value decreasing from 0.003 to 0.0025 at $30 \mathrm{~m} \mathrm{~s}^{-1}$ (Figure 8c-d). For low wind speeds, high drag values correspond to the viscous laminar flow (Eq. (4)). In comparison with high winds observations, the parameterization [4] gives lower drag values than default ECMWF.

Finally, the fifth parameterization ([5]) is without wave feedback, using a constant Charnock parameter of 0.018 in IFS.

We simulated Kaat and Lilli storms from 23 to 27 February 2014, with the five parameterizations described above. The resulting Charnock parameters and drag coefficients were extracted on a $0.125^{\circ}$ grid over the North East Atlantic (Figure 9). The parameterization [3] gives the strongest values of Charnock, leading to high values of drag, above 0.003 for wind speeds above $25 \mathrm{~m} \mathrm{~s}^{-1}$. These drag values are unrealistic compared with observations (Figure 7). The wave-age-dependent parameterization [3] is based on an experiment with winds ranging from 6 to $18 \mathrm{~m} \mathrm{~s}^{-1}$ : when extrapolating this relation to higher winds, 
unrealistically high drag coefficients are produced. The WW3 physics parameterization [2] is close to the default ECMWF parameterization, but with less variability of $C_{d}$ as a function of wave age. This could be adjusted with fine tuning parameters, particularly by decreasing the sheltering coefficient. The empirically-adjusted Charnock parameterization [4] helps reducing the Charnock parameter and drag coefficient compared with ECMWF parameterization, leading to the lowest drag values, even lower than the constant Charnock parameter: $C_{d}$ reaches 0.002 at $36 \mathrm{~m} \mathrm{~s}^{-1}$, instead of 0.0027 for a constant Charnock.

\subsection{Results}

Considering alternative parameterizations, we expect to have stronger winds, compared to those obtained with the default ECMWF parameterization. Simulations were carried out from 23 to 27 January 2014. ECWAM computes (i) wave-induced stress following Eq. (7), (ii) total stress from tabulated solution of (1), (2) and (5) depending on 10-m wind speed (coming from the atmospheric model) and wave-induced stress, (iii) roughness length following Eq. (5) and (6), (iv) and finally the Charnock parameter following the second part of Eq. (4) which passes into the atmosphere. Then, IFS computes (i) $\mathrm{u} *$ and $\mathrm{z}_{0}$ following Eq. (4), (ii) the drag following Eq. (3), (iii) and then $U_{10}$ following Eq. (2), which is sent on to ECWAM.

For mid-latitude storms such as Kaat and Lilli, a larger Charnock parameter generally leads to a larger roughness length (not shown), a higher drag coefficient, higher wind stress, and lower wind speed (Figure 10). Conversely, a lower Charnock parameter leads to higher wind speed and lower central surface pressure in the storm. The wave-age dependency of the Charnock parameter is based on the fact that young - compared to old - waves are steeper and lead to a higher roughness length (expressed as Eq. (5) in Janssen et al., 1991). However, the roughness length is still physically difficult to interpret. It is not a direct measurable parameter over the ocean, but generally deduced from other measurements (for example wind 
measurements at different heights, and application of logarithmic formula to infer the roughness length). When roughness increases, friction also increases and slows the wind down. As the wind decreases, the feedback effect results in a smoother sea state, possibly leading in turn to a reduced friction velocity and consequently to increased wind speed.

The use of the WW3-physics-based parameterization [2] instead of the ECMWF default parameterization [1] (Figure 10b) leads to slightly lower Charnock values, and consequently marginally higher wind speeds. The wave age dependent parameterization [3] (Figure 10c) gives higher Charnock values and lower winds. This is due to unrealistic extrapolation to high winds of a relation based on winds ranging from 6 to $18 \mathrm{~m} \mathrm{~s}^{-1}$ (Oost et al., 2002). Finally, an empirically-adjusted Charnock parameterization [4] (Figure 10d) leads to lower Charnock parameters and stronger high winds than with ECMWF parameterization. Winds become close to but lower than constant Charnock parameterization (Figure 10e). For winds above 30 $\mathrm{m} \mathrm{s}^{-1}$, the parameterization [4] gives higher winds than with the constant Charnock parameterization [5], as the adjusted Charnock parameter is lower than 0.018 (Figure 9a).

To estimate the impact of the new wind stress parameterization [4], we computed biases between winds from the model and the observations for the default ECMWF and the empirically-adjusted Charnock parameterizations. The new parameterization efficiently reduces the bias by about $2 \mathrm{~m} \mathrm{~s}^{-1}$ at $30 \mathrm{~m} \mathrm{~s}^{-1}$ for ASCAT-KNMI, ASCAT-RSS, AMSR2 and WindSat (Figure 11a-b-c-d-f). This demonstrates that adjusting the parameterization is one way of obtaining winds closer to satellite estimates, in particular radiometer estimates.

The bias (Figure 11e) between the wind speeds obtained with the default ECMWF and buoy observations is close to zero, and the new parameterization leads to a positive bias, i.e. simulated winds higher than buoy winds. 
Although this new parameterization certainly improves high winds, there is still a negative bias with the majority of observations. The effective ECWMF model resolution (about 6 to 8 times the 16-km spatial resolution for the TL1279 Gaussian grid) might be too coarse to represent accurately high winds as in the case of satellite products, which have a resolution of $0.125^{\circ}$. Moreover, initial conditions come from the ECMWF operational analysis, and the data assimilation process used in the operational system may prevent high winds from ASCAT from being integrated adequately: (1) ASCAT data are systematically corrected from a possible bias with the model, (2) some strong ASCAT winds can be rejected prior to assimilation, partially because of the thinning applied (only one observation out of four is assimilated) and quality control (De Chiara et al., 2016); an alternative method to the current quality control is under testing at ECMWF. On the top of that (see the discussion section 4.3) observations can also be biased at high wind speed.

\section{Conclusions}

We started this work because different atmospheric models had different biases on the wind speed in storm conditions, possibly due to different surface drag parameterizations. The objectives were (1) to evaluate ECMWF strong winds against observations, (2) to test how an alternative wind stress parameterization could lead to a more accurate model. During Kaat and Lilli storms (23 to 27 January 2014), we compared simulated winds from ECMWF coupled wave-atmosphere model with in-situ and satellite observations available in the North Atlantic. We then developed an empirically-adjusted Charnock parameterization, to obtain winds closer to observations.

The first result is that moderate simulated winds $\left(5-20 \mathrm{~m} \mathrm{~s}^{-1}\right)$ agree well with both in situ and satellite observations, whereas strong winds (above $20 \mathrm{~m} \mathrm{~s}^{-1}$ ) are generally underestimated compared with observations; the negative bias can reach $-7 \mathrm{~m} \mathrm{~s}^{-1}$ at $30 \mathrm{~m} \mathrm{~s}^{-1}$. 
The second result is that biases exist between observations. We identified two groups of data. The first one, composed of buoys and ASCAT-KNMI, gives lower strong winds than the second one, which is composed of platforms and other remote sensing data used in this study (AMSR2, ASCAT-RSS, WindSat, SMOS and JASON-2). It is difficult to conclude which dataset should be used as a reference, but buoys and ASCAT-KNMI winds are likely to be underestimated.

Lastly, the third result is that a newly empirically-adjusted Charnock parameterization would lead to higher winds than the default ECMWF ones. Yet, common wave-age dependent parameterization gives larger drag coefficients than measurements - and lower winds - and is not appropriate for coupling.

This study was then reproduced for three other storms in the North East Atlantic: Alexandra (8 December 2014), Erich (10 March 2015) and Uwe (7 December 2015); results are similar and confirm these conclusions. Moreover, NASA/SMAP data were also exploited for Uwe, showing similar biases with the model consistent with WindSat and SMOS (Meissner et al., 2017).

While this sensitivity study shows the impact of drag parameterizations on winds, a next step is needed to study how the atmosphere evolves and adjusts, particularly the $500 \mathrm{hPa}$ geopotential. Similar work should be further undertaken to study the impact of the drag on the ocean circulation.

The significant bias between buoy and platform strong winds suggests that in situ measurements should be handled with particular care. Despite investigation, it is finally not clear what the "surface wind reference" should be, and where the "truth" lies. More dedicated investigations are necessary to document the respective quality of in-situ wind measurements 
for high winds better. More datasets representing extreme conditions are needed, in order to validate models and to calibrate remote sensing instruments.

Indeed, the role of the wind datasets in building the GMFs is essential and different datasets lead to different GMFs. As a consequence, ASCAT-KNMI strong winds show a systematic negative bias with respect to ASCAT-RSS ones.

Not surprisingly, the sensitivity of the atmosphere to drag parameterizations shows that stronger winds can be obtained. Our limited simulations do not show a big impact on the overall atmospheric circulation but more tests will have to be performed before our alternative parameterization is considered for operational applications.

From a physical point of view, the drag is expected to combine various processes including air flow separation over breaking waves (e.g. Reul et al., 1999; 2008, Kudryavtsev et al., 2014), which is is not represented in the quasi-linear model of Fabrikant (1976) and Janssen (1986) on which the ECMWF parameterization is based. Also, Janssen's parameterization (Eq. (5)) produces a ratio $\tau_{w} / \tau$ that is often very close to 1 for young seas and is very sensitive to the high frequency spectrum tail, a part of the spectrum that is very crudely represented in wave models today (Kudryavtsev et al., 2014, Peureux and Ardhuin, 2016).

Finally, high-quality strong winds from in-situ and remote sensing are essential, as these data are assimilated in Numerical Weather Prediction models. In the near future, MetOp-Second Generation (MetOp-SG) will be launched after 2020 and will include on board a C-band scatterometer with co-polarization (VV, similar to ASCAT), but also cross-polarization (VH). The addition of VH-polarization will significantly improve strong winds retrieval (e.g. Zhang and Perrie 2012, Mouche et al., 2017). 


\section{Acknowledgments}

This work was performed as part of an ECMWF "special project", which provided access to ECMWF computing and archive facilities in this research. We thank all ECMWF staff for the warm welcome and excellent support provided to LPG, FA and MNB. KNMI (Royal Netherlands Meteorological Institute), SOLab (Satellite Oceanography Laboratory, Russian State Hydrometeorological University), Remote Sensing Systems (RSS), NASA PODAAC and CNES Aviso provided remote sensing data, and Germany's National Meteorological Service provided synoptic charts. We also thank O. Breivik and Norwegian Meteorological Institute for providing wind measurements from Norwegian platforms. We warmly thank Glyn Orpwood for his great help in improving the written English. Finally, the authors would like to thank reviewers for their careful reading and their constructive comments, which allowed this paper to be improved.

\section{Appendix A: Mean Charnock for empirically-adjusted parameterization}

The table A1 gives the values of the mean Charnock given by default ECMWF parameterization. Values are computed every $1 \mathrm{~m} \mathrm{~s}^{-1}$ bin, from the full year 2014 of global IFS simulations. These tables are used for emirically-adjusted Charnock parameterization.

Table A1

Appendix B: Standard deviations and root mean square errors between ECMWF simulated winds and observations

The figures B1 and B2 show standard deviation and Root Mean Square (RMS) errors between ECMWF model (CY41R1) and observations (buoys, platforms, and satellite data), computed 
from 23 to 27 January 2014 on the North East Atlantic. The last binned values have large standard deviations because they represent only a few points.

Figure B1

Figure B2

\section{References}

Andreas EL. 2009. Relating the drag coefficient and the roughness length over the sea to the wavelength of the peak waves. J. Phys. Oceanogr. 39: 3011 - 3020.

Ardhuin F, Chapron B, Collard F. 2009. Observation of swell dissipation across oceans. Geophys. Res. Lett. 36: L06607. DOI: 10.1029/2008GL037030

Ardhuin F, Rogers E, Babanin AV, Filipot J, Magne R, Roland A, van der Westhuysen A, Queffeulou P, Lefevre J, Aouf L, Collard F. 2010. Semi empirical dissipation source functions for ocean waves. Part I: definition, calibration, and validation. J. Phys. Oceanogr. 40 (9): $1917-1941$

Bentamy A, Croize-Fillon D, Perigaud C. 2008. Characterization of ASCAT measurements based on buoy and QuikSCAT wind vector observations. Ocean Science 4: 265-274.DOI: 10.5194/os-4-265-2008

Black PG, D’Asaro EA, Drennan WM, French JR, Niller PP, Sanford TB, Terrill EJ, Walsh EJ, Zhang JA. 2007. Air-sea exchange in hurricanes: synthesis of observations from the coupled boundary layer air-sea transfer experiment. Am. Meteorol. Soc. 88: 359-374

Chapron B, Bingham A, Collard F, Donlon C, Johannessen JA, Piolle JF, Reul N. 2010. Ocean remote sensing data integration — Examples and outlook. OceanObs' 09: Sustained ocean observations and information for society (Vol. 1), Venice, Italy, 21-25 September 2009. Charnock H. 1955. Wind stress on a water surface. Q J Roy Meteor Soc. 81: 639-640 
Chou KH, Wu CC, Lin SZ. 2013. Assessment of the ASCAT wind error characteristics by global dropwindsonde observations. J. Geophys. Res. Atmos. 118: 9011-9021. DOI: 10.1002/jgrd.50724

De Chiara G, English S, Janssen P, Bidlot JR. 2016. ASCAT ocean surface wind assessment. ECMWF Technical Memorandum 776.

Dee DP, Uppala SM, Simmons AJ, Berrisford P, Poli P, Kobayashi S, Andrae U, Balmaseda MA, Balsamo G, Bauer P, Bechtold P, Beljaars ACM, van de Berg L, Bidlot J, Bormann N, Delsol C, Dragani R, Fuentes M, Geer AJ, Haimberger L, Healy SB, Hersbach H, Hólm EV, Isaksen L, Kållberg P, Köhler M, Matricardi M, McNally AP, Monge-Sanz BM, Morcrette JJ, Park BK, Peubey C, de Rosnay P, Tavolato C, Thépaut JN, Vitart F. 2011. The ERA-Interim reanalysis: Configuration and performance of the data assimilation system. Quart. J. R. Meteorol. Soc. 137: 553-597. DOI: 10.1002/qj.828

Donelan MA. 1982. The dependence of the aerodynamic drag coefficient on wave parameters. Paper presented at 1st International Conference on Meteorology and Air-Sea Interaction of the Coastal Zone, Am. Meteorol. Soc., Boston, Mass.

Donelan MA, Haus BK, Reul N, Plant WJ, Stiassnie M, Graber HC, Brown OB, Saltzman ES. 2004. On the limiting aerodynamic roughness of the ocean in very strong winds. Geophys. Res. Lett. 31: L18306. DOI: 10.1029/2004GL019460

Drennan WB, Graber HC, Hauser D, Quentin C. 2003. On the wave age dependence of wind stress over pure wind seas. J. of Geophys. Res.: Oceans 108: 8062. DOI: 10.1029/2000JC000715

ECMWF. 2015a. IFS Documentation CY41R1. ECMWF Book.

ECMWF. 2015b. IFS Documentation CY41R1. Part VII: ECMWF Wave Model. ECMWF Book Chapter. 
Edson JB, Jampana V, Weller RA, Bigorre SP, Plueddemann AJ, Fairall CW, Miller SD, Mahrt L, Vickers D, Hersbach H. 2013. On the exchange of momentum over the open ocean. J. Phys. Oceanogr. 43(8): 1589-1610. DOI: 10.1175/JPO-D-12-0173.1

Fabrikant AL. 1976. Quasilinear theory of wind-wave generation. Izv. atmos. ocean. Phys. 12 (524)

Furevik BR, Haakenstad H. 2012. Near-surface marine wind profiles from rawinsonde and NORA10 hindcast. J. Geophys. Res. 117: D23106. DOI: 10.1029/2012JD018523

Gaiser PW, St. Germain KM, Twarog EM, Poe GA, Purdy W, Richardson D, Grossman W, Jones LW, Spencer D, Golba G, Cleveland J, Choy L, Bevilacqua RM, Chang PS. 2004. TheWindSat spaceborne polarimetric microwave radiometer: Sensor description and early orbit performance. IEEE Trans. Geosci. Remote Sens. 42 (11): 2347-2361

Hanafin J, Quilfen Y, Ardhuin F, Sienkiewicz J, Queffeulou P, Obrebski M, Chapron B, Reul N, Collard F, Corman D, De Azevedo EB, Vandemark D, Stutzmann E. 2012. Phenomenal sea states and swell from a North Atlantic Storm in February 2011: a comprehensive analysis. Bulletin Of The American Meteorological Society 93: 1825-1832. DOI: 10.1175/BAMS-D$11-00128.1$

Hoskins BJ, Hodges KI. 2002. New perspectives on the Northern Hemisphere winter storm tracks. J Atmos Sci 59:1041-1061

Janssen PAEM. 1986. On the effect of gustiness on wave growth. KNMI Afdeling Oceanografisch Onderzoek memo 00-86-18. De Bilt, 17p.

Janssen PAEM. 1991. Quasi-linear theory of wind-wave generation applied to wave forecasting. J. Phys. Oceanogr. 21: 1631-1642

Janssen PAEM. 1994. Results with a coupled wind wave model. ECMWF Technical Report $n^{\circ} 71$. 
Janssen PAEM. 2004. The interaction of ocean waves and wind. Cambridge University Press. Jarosz ED, Mitchell A, Wang DW, Teague WJ. 2007. Bottom-up determination of air-sea momentum exchange under a major tropical cyclone. Science 315: 1707-1709. DOI: 10.1126/science.1136466.

Kazumori M, Geer AJ, English SJ. 2016. Effects of all-sky assimilation of GCOMW/AMSR2 radiances in the ECMWF numerical weather prediction system. Q.J.R. Meteorol. Soc. 142: 721-737. DOI: 10.1002/qj.2669

Komen G, Janssen PAEM, Makin V, Oost W. 1998. On the sea state dependence of the Charnock parameter. Global Atmos. Ocean. Syst. 5: 367-388.

Kudryavtsev V, Chapron B, Makin V. 2014. Impact of wind waves on the air-sea fluxes: A coupled model, J. Geophys. Res. Oceans 119: 1217-1236. DOI: 10.1002/2013JC009412.

Meissner T, Wentz FJ. 2009. Wind-vector retrievals under rain with passive satellite microwave radiometers. IEEE Trans. Geosci. Remote Sens. 47 (9): 3065-3083.

Meissner T, Ricciardulli L, Wentz F. 2017. Capability of the SMAP Mission to Measure Ocean Surface Winds in Storms. Bull. Amer. Meteor. Soc. in press DOI: 10.1175/BAMS-D$16-0052.1$

Mastenbroek C, Burgers G, Janssen PAEM. 1993. The dynamical coupling of a wave model and a storm surge model through the Atmospheric Boundary Layer. Journal of physical Oceanography 23: 1856-1866.

Mouche AA, Chapron B, Zhang B, Husson R. 2017. Combined co- and cross- polarized SAR measurements under extreme wind conditions. IEEE Trans. Geosci. Remote Sen. PP (99) : 110. DOI: $10.1109 /$ TGRS.2017.2732508 
Muller H, Pineau-Guillou L, Idier D, Ardhuin F. 2014. Atmospheric storm surge modeling methodology along the French (Atlantic and English Channel) coast. Ocean Dynamics 64(11): 1671-1692. DOI: 10.1007/s10236-014-0771-0

Oost WA., Komen GJ, Jacobs CMJ, van Oort C. 2002. New evidence for a relation between wind stress and wave age from measurements during ASGAMAGE. Boundary-Layer Meteorology 103(3): 409-438

Peureux C, Ardhuin F. 2016. Ocean bottom pressure records from the Cascadia array and short surface gravity waves. J. Geophys. Res. Oceans 121(5): 2862-2873

Phillips OM. 1985. Spectral and statistical properties of the equilibrium range in windgenerated gravity waves. J. Fluid Mech. 156: 505-531.

Powell MD, Vickery PJ, Reinhold TA. 2003. Reduced drag coefficient for high wind speeds in tropical cyclones. Nature 422: 279-283

Quilfen Y, Chapron B, Bentamy A, Gourrion J, Elfouhaily T, Vandemark D. 1999. Global ERS 1 and 2 and NSCAT observations: Upwind crosswind and upwind downwind measurements. Journal Of Geophysical Research-oceans 104: 11459-11469. DOI: 10.1029/1998JC900113

Quilfen Y, Tournadre J, Chapron B. 2006. Altimeter dual-frequency observations of surface winds, waves, and rain rate in tropical cyclone Isabel. Journal of Geophysical Research 111. DOI: 10.1029/2005JC003068

Quilfen Y, Prigent C, Chapron B, Mouche A, Houti N. 2007. The potential of QuikSCAT and WindSat observations for the estimation of sea surface wind vector under severe weather conditions. Journal of Geophysical Research 112. DOI: 10.1029/2007JC004163 
Quilfen Y, Vandemark D, Chapron B, Feng H, Sienkiewicz J. 2011. Estimating Gale to Hurricane Force Winds Using the Satellite Altimeter. Journal Of Atmospheric And Oceanic Technology 28: 453-458. DOI: 10.1175/JTECH-D-10-05000.1

Rascle N, Ardhuin F. 2013. A global wave parameter database for geophysical applications. Part 2: Model validation with improved source term parameterization. Ocean Modelling 70: 174-188

Reul N, Branger H, and Giovanangeli JP. 1999. Air flow separation over unsteady breaking waves. Phys. Fluids 11: 1959-1961. DOI: 10.1063/1.870058

Reul N, Branger H, Giovanangeli JP. 2008. Air Flow Structure Over Short-gravity Breaking Water Waves. Boundary-Layer Meteorology 126(3): 477-505. DOI: 10.1007/s10546-007$9240-3$

Reul N, Tenerelli J, Chapron B, Vandemark D, Quilfen Y, Kerr Y. 2012. SMOS satellite Lband radiometer: A new capability for ocean surface remote sensing in hurricanes. Journal of Geophysical Research 117: C02006. DOI: 10.1029/2011JC007474.

Reul N, Chapron B, Zabolotskikh E, Donlon C, Quilfen Y, Guimbard S, Piolle JF. 2016. A revised L-band radio-brightness sensitivity to extreme winds under tropical cyclones: The 5 year SMOS-Storm database. Remote Sensing Of Environment 180: 274-291

Reul N, Chapron B, Zabolotskikh E, Donion C, Mouche A, Tenerelli J, Collard F, Piolle JF, Fore A, Yueh S, Cotton J, Francis P, Quilfen Y, Kudryavtsev V. 2017. A new generation of Tropical Cyclone Size measurements from space. Bull. Amer. Meteor. Soc. DOI: 10.1175/BAMS-D-15-00291.1, in press.

Saha S, Moorthi S, Pan HL, Wu X, Wang J, Nadiga S, Tripp P, Kistler R, Woollen J, Behringer D, Liu H, Stokes D, Grumbine R, Gayno G, Wang J, Hou YT, Chuang HY, Juang HMH, Iredell M, Treadon R, Kleist D, Delst PV, Keyser D, Derber J, Ek M, Meng J, Wei H, 
Yang R, Lord S, van den Dool H, Kumar A, Wang W, Long C, Chelliah M, Xue Y, Huang B, Schemm JK, Ebisuzaki W, Lin R, Xie P, Chen M, Zhou S, Higgins W, Zou CZ, Liu Q, Chen Y, Han Y, Cucurull L, Reynolds RW, Rutledge G, Goldberg M. 2010. The NCEP climate forecast system reanalysis. Bull. Am. Meteorol. Soc. 90 (8): 1015-1057

Sapp JW, Alsweiss SO, Jelenak Z, Chang PS, Frasier SJ, Carswell J. 2016. Airborne copolarization and cross-polarization observations of the ocean-surface nrcs at c-band. IEEE Trans. Geosci. Remote Sen. 54(10): 5975-5992.

Shimura T, Mori N, Takemi T, Mizuta R. 2017. Long-term impacts of ocean wave-dependent roughness on global climate systems. J. Geophys. Res. Oceans 122:1995-2011. DOI:10.1002/2016JC012621.

Skey SGP, Berger-North K, Swail VR. 1995. Detailed measurements of winds and waves in high sea states from a moored NOMAD water buoy. Proc. Fourth Int. Workshop on Wave Hindcasting and Forecasting, Banff, AB, Canada, 213-223.

Takagaki N, Komori S, Suzuki N, Iwano K, Kuramoto T, Shimada S, Kurose R, Takahashi K. 2012. Strong correlation between the drag coefficient and the shape of the wind sea spectrum over a broad range of wind speeds. Geophys Res Lett 39:1-6. DOI: 10.1029/2012GL053988 Verspeek J, Stoffelen A, Verhoef A, Portabella M. 2012. Improved ASCAT wind retrieval using NWP ocean calibration. IEEE Trans. Geosci. Remote Sens. 50(7): 2488-2494.

The WAVEWATCH III® Development Group (WW3DG). 2016. User manual and system documentation of WAVEWATCH III ${ }^{\circledR}$ version 5.16. Tech. Note 329, NOAA/NWS/NCEP/MMAB, College Park, MD, USA, 326 pp. + Appendices.

Zabolotskikh EV, Mitnik LM, Chapron B. 2013. New approach for severe marine weather study using satellite passive microwave sensing. Geophysical Research Letters 40(13): 33473350. DOI:10.1002/grl.50664 
Zabolotskikh E, Mitnik L, Chapron B. 2014. GCOM-W1 AMSR2 and MetOp-A ASCAT wind speeds for the extratropical cyclones over the North Atlantic. Remote Sensing Of Environment 147: 89-98.

Zhang B, Perrie W. 2012. Cross-polarized synthetic aperture radar: A new potential technique for hurricanes, Bull. Am. Meteorol. Soc. 93: 531-541. DOI: 10.117 5/BAMS-D-11-00001.1

Zeng L, Brown RA. 1998. Scatterometer observations at high wind speeds. Journal of Applied Meteorology 37(11): 1412-1420 
Figure 1. DWD synoptic charts on 24 and 26 January 1200 UTC

Figure 2. Kaat and Lilli storm tracks on January 2014 (data every 6 hours). In black dotted line are shown the principal tracks from Hoskins and Hodges (2002)

Figure 3. Wind field on 26 January 2014 estimated from ASCAT-KNMI Metop-A (a), ASCAT-RSS Metop-A (b), AMSR2 (c), WindSat (d) for descending passes, and for SMOS (e) and JASON-2 (f). Platforms and buoys are plotted on (a).

Figure 4. Wind correlations from 23 to 27 of January 2014 between default ECMWF parameterization (CY41R1) and ASCAT-KNMI (a), ASCAT-RSS (b), AMSR2 (c), WindSat (d), SMOS (e), JASON-2 (f), buoys (g) and platforms (h)

Figure 5. Wind biases between ECMWF (CY41R1) model and observations (buoys, platforms, and satellite data), computed from 23 to 27 January 2014 on the North East Atlantic. Beyond $30 \mathrm{~m} . \mathrm{s}^{-1}$, values are plotted as points, due to large uncertainties on observations.

Figure 6. Wind biases between ECMWF (CY41R1) model and observations (buoys, platforms, and satellite data), computed on the North East Atlantic for storms (a) Kaat/Lilli (b) Alexandra (c) Erich (d) Uwe. Beyond $30 \mathrm{~m} \cdot \mathrm{s}^{-1}$, values are plotted as points, due to large uncertainties on observations.

Figure 7. Comparison of drag coefficient for ECMWF (CY41R1) parameterization, empirically-adjusted Charnock parameterization and observations (Donelan et al., 2004, "R" or "M" corresponds to different measurements techniques "Reynolds" or "Momentum Budget”). Error bars correspond to one standard deviation.

Figure 8. Charnock parameter (a,b) and drag coefficient (c,d) during Kaat and Lilli storms from 23 to 27 January 2014, with ECMWF (CY41R1) parameterization (left) and 
empirically-adjusted Charnock parameterization (right). Error bars correspond to one standard deviation.

Figure 9. Charnock parameter (a) and drag coefficient (b) during Kaat and Lilli storms (from 23 to 27 January 2014), for the five tested parameterizations. Error bars correspond to one standard deviation.

Figure 10. Impact of different parameterizations on Charnock, drag coefficient, wind stress and wind on 26 January 2014 at 1200 UTC

Figure 11. 10-m wind speed biases, on the period 23 to 27 of January 2014 on the North East Atlantic, between (a) ASCAT-KNMI, (b) ASCAT-RSS, (c)AMSR2, (d) WindSat, (e) buoys, (f) platforms and model for the default ECMWF CY41R1 (blue) and empirically-adjusted (red) parameterizations. Beyond $30 \mathrm{~m} . \mathrm{s}^{-1}$, values are plotted as points, due to large uncertainties on observations.

Figure B1. Standard deviation between ECMWF model (CY41R1) and observations (buoys, platforms, and satellite data), computed from 23 to 27 January 2014 on the North East Atlantic

Figure B2. Root Mean Square (RMS) errors between ECMWF model (CY41R1) and observations (buoys, platforms, and satellite data), computed from 23 to 27 January 2014 on the North East Atlantic

Table 1. Maximum of wind, wind gust, minimum of Mean Sea Level (MSL) pressure, maximum significant wave height $\left(\mathrm{H}_{\mathrm{s}}\right)$, and precipitation over 24 hours for the 10 more energetic events, based on ERA-Interim analysis over period 2005-2015 over the North East Atlantic.

Table 2. Main characteristics of satellite wind products on 26 January 2014 over the North East Atlantic, and number of points for collocation. 
Table 3. Correlation coefficients (r) between ECMWF simulated winds and observations from 23 to 27 January 2014, over the North East Atlantic.

Table 4. Wind stress parameterizations tested in this study

Table A1. Mean Charnock tables for empirically-adjusted Charnock parameterization, based on 2014 year analysis 


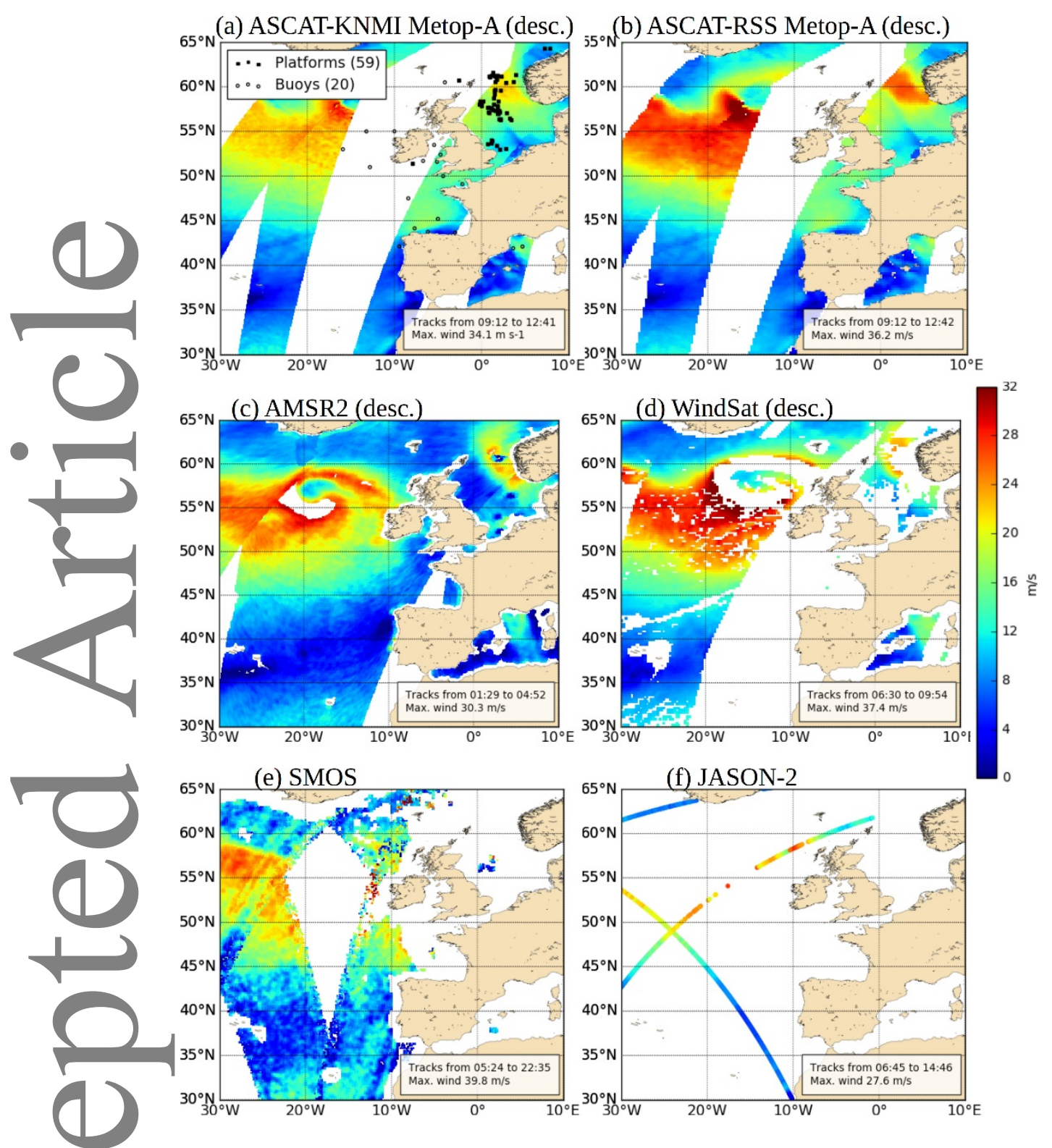

Fig 3 
(a) Charnock - ECMWF (CY41R1)

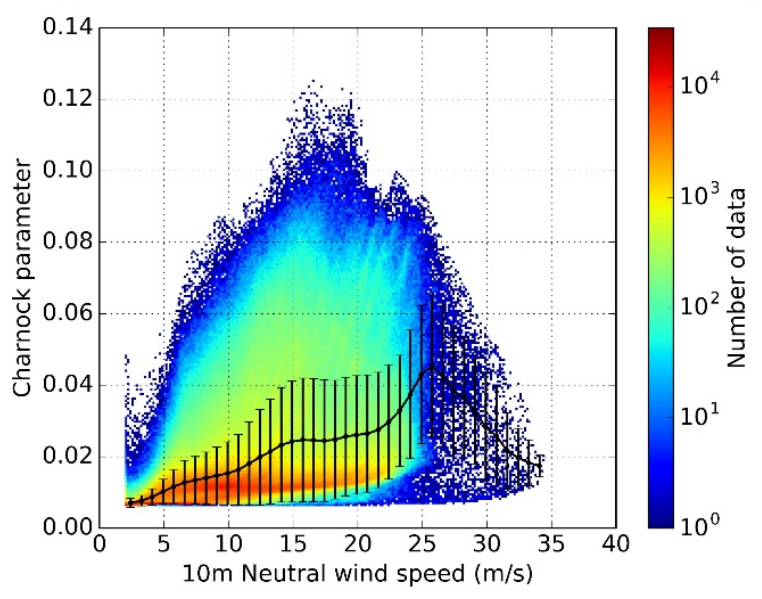

(c) Drag - ECMWF (CY41R1)

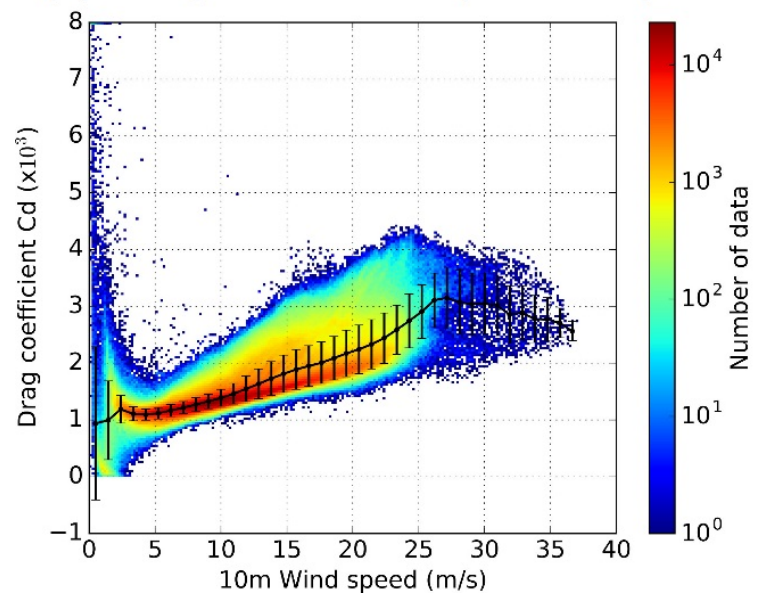

(b) Charnock - This study

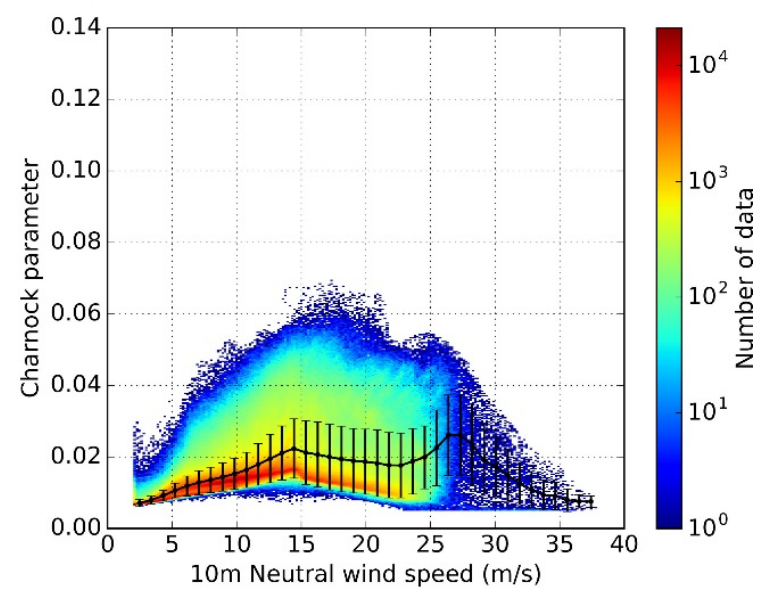

(d) Drag - This study

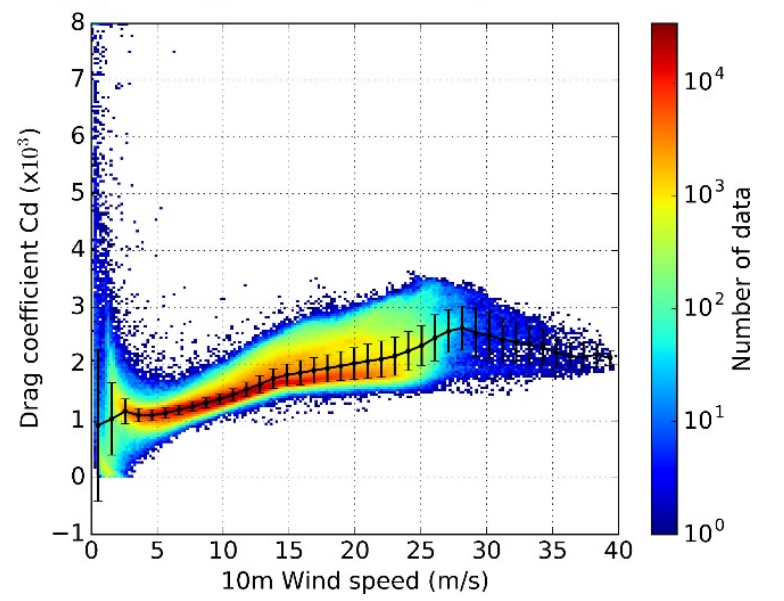

Fig 9

(a) Charnock

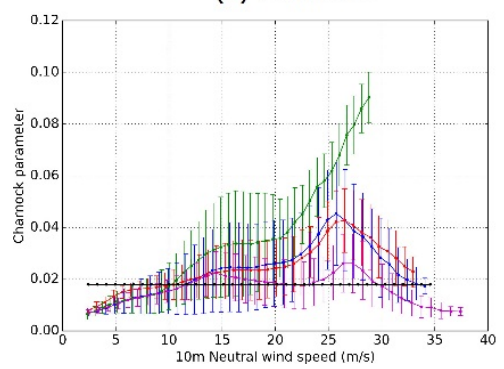

(b) Drag

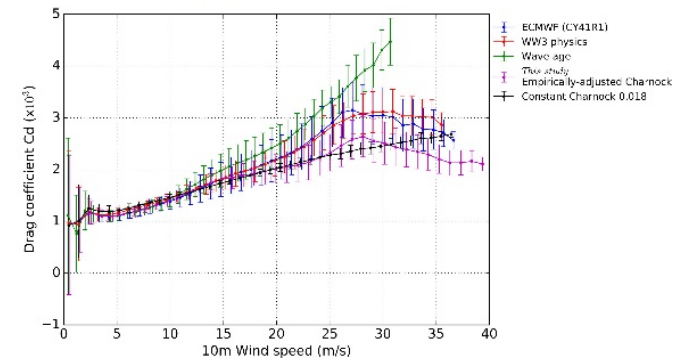


(a) ASCAT-KNMI

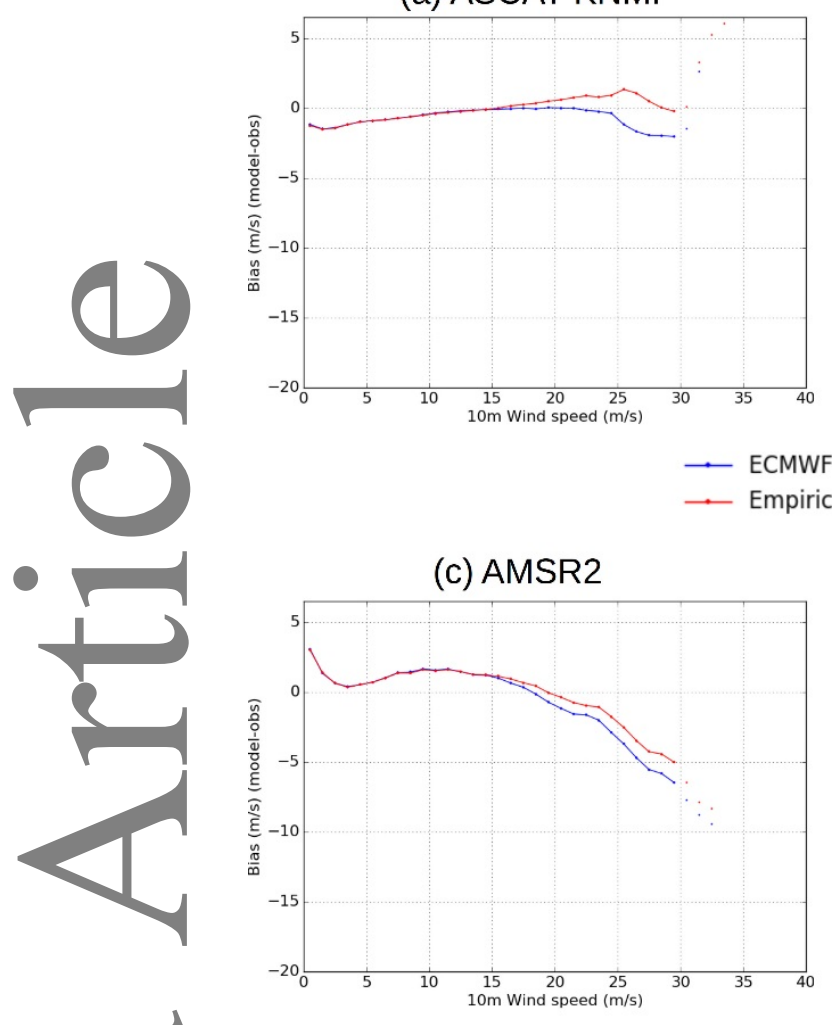

(e) Buoys

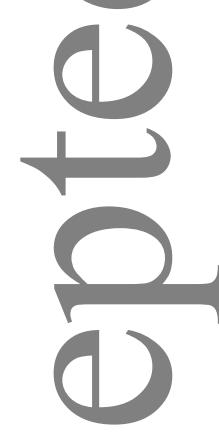

0

ن

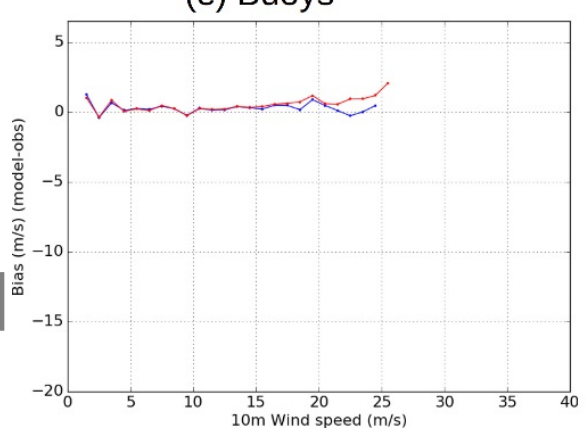

(b) ASCAT-RSS

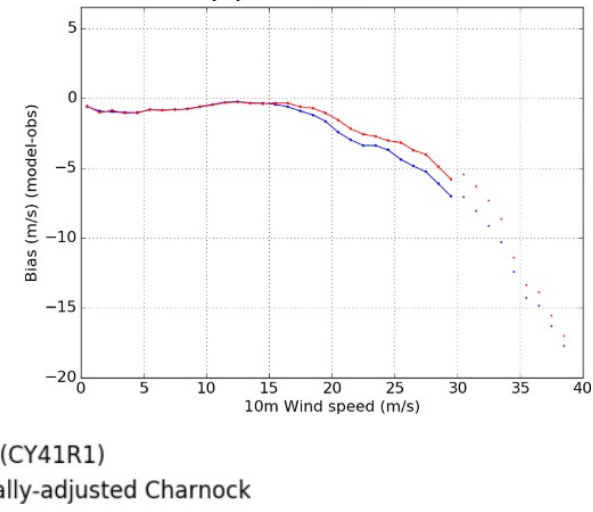

(d) WindSat

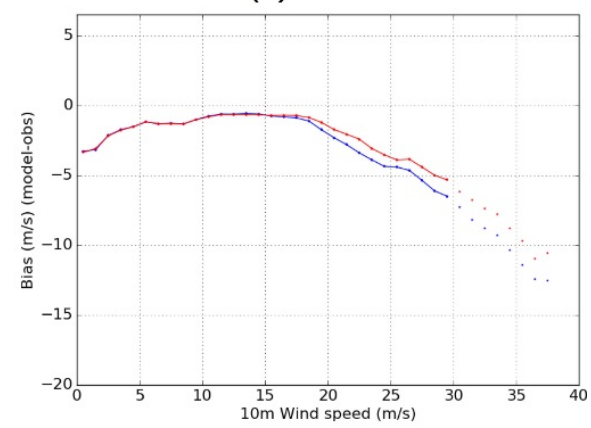

(f) Platforms

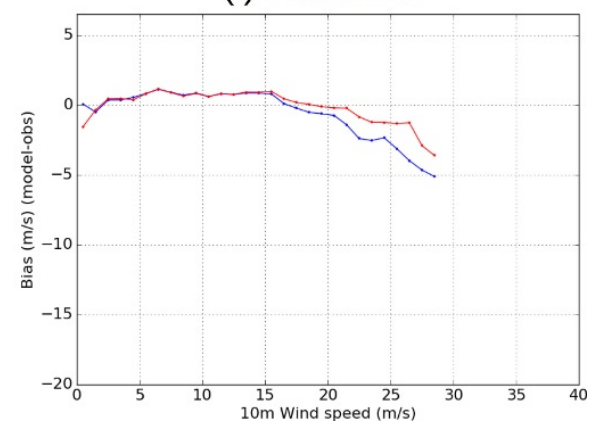




\begin{tabular}{|c|c|c|c|c|c|c|c|}
\hline Date & Rank & Name & $\begin{array}{l}\text { Wind } \\
\left(\mathrm{m} \mathrm{s}^{-1}\right)\end{array}$ & $\begin{array}{l}\text { Wind } \\
\text { Gust } \\
\left(\mathrm{m} \mathrm{s}^{-1}\right) \\
\end{array}$ & $\begin{array}{c}\text { MSL } \\
\text { Pressure } \\
(\mathrm{hPa})\end{array}$ & $\begin{array}{l}\text { Hs } \\
\text { (m) }\end{array}$ & $\begin{array}{c}\text { Prec. } \\
(\mathrm{mm} \text { per } 24 \mathrm{~h})\end{array}$ \\
\hline $2005-09-26$ & 10 & Zeljko & 35.9 & 46.3 & 967 & 8.2 & 27 \\
\hline 2006-12-09 & 7 & Xynthia & 37.6 & 50.4 & 951 & 9.0 & 29 \\
\hline $2007-12-10$ & 3 & No name & 39.0 & 54.0 & 963 & 7.5 & 30 \\
\hline $2009-01-23$ & 1 & Hans/Klaus & 41.8 & 37.8 & 944 & 9.4 & 44 \\
\hline $2013-12-15$ & 9 & Zaki & 36.9 & 48.0 & 957 & 9.7 & 27 \\
\hline 2014-01-25 & 5 & Kaat/Lilli & 38.1 & 56.3 & 953 & 11.7 & 31 \\
\hline 2014-12-08 & 2 & Alexandra & 39.6 & 45.5 & 964 & 7.8 & 25 \\
\hline 2015-01-19 & 8 & Jan & 37.0 & 51.7 & 974 & 9.9 & 26 \\
\hline $2015-03-10$ & 4 & Erich & 38.2 & 52.6 & 966 & 7.8 & 28 \\
\hline $2015-12-07$ & 6 & Uwe & 37.9 & 57.9 & 959 & 6.8 & 38 \\
\hline
\end{tabular}

Table 1. Maximum of wind, wind gust, minimum of Mean Sea Level (MSL) pressure, maximum significant wave height $\left(\mathrm{H}_{\mathrm{s}}\right)$, and precipitation over 24 hours for the 10 more energetic events, based on ERA-Interim analysis over period 2005-2015 over the North East Atlantic.

\begin{tabular}{ccccccc}
\hline Instrument & Satellite & $\begin{array}{c}\text { Data } \\
\text { provider }\end{array}$ & $\begin{array}{c}\text { Swath Width } \\
(\mathrm{km})\end{array}$ & $\begin{array}{c}\text { Wind product } \\
\text { sampling }(\mathrm{km})\end{array}$ & $\begin{array}{c}\text { Max. } \\
\text { wind } \\
\left(\mathrm{m} \mathrm{s}^{-1}\right)\end{array}$ & $\begin{array}{c}\text { Nb of points } \\
\text { for } \\
\text { collocation }\end{array}$ \\
\hline ASCAT & Metop-A/B & KNMI & $2 * 512.5$ & 12.5 & 36.2 & 367032 \\
ASCAT & Metop-A & RSS & $2 * 512.5$ & 27 & 34.1 & 43469 \\
AMSR2 & GCOM-W1 & SOLab & 1450 & 10 & 31.9 & 166803 \\
WindSat & Coriolis & RSS & 1000 & 25 & 37.4 & 35974 \\
MIRAS & SMOS & Ifremer & 600 & 15 & 39.8 & 31622 \\
Poséidon-3 & JASON-2 & NASA & $/$ & 6 & 27.6 & 4868 \\
Buoys & & & & & & \\
Platforms & & & & & & \\
\hline
\end{tabular}

Table 2. Main characteristics of satellite wind products on 26 January 2014 over the North East Atlantic, and number of points for collocation. 


\begin{tabular}{cccc}
\hline Instrument & Satellite & Data provider & Correlation coefficient (r) \\
\hline ASCAT & Metop-A/B & KNMI & 0.95 \\
ASCAT & Metop-A & RSS & 0.94 \\
AMSR2 & GCOM-W1 & SOLab & 0.90 \\
WindSat & Coriolis & RSS & 0.94 \\
MIRAS & SMOS & Ifremer & 0.79 \\
Poséidon-3 & JASON-2 & NASA & 0.92 \\
Buoys & & & 0.91 \\
Platforms & & & 0.91 \\
\hline
\end{tabular}

Table 3. Correlation coefficients (r) between ECMWF simulated winds and observations from 23 to 27 January 2014, over the North East Atlantic.

\begin{tabular}{ll}
\hline Parameterization & Reference \\
\hline [1] Coupled ECWAM/IFS with default ECMWF parameterization & Janssen 1991 \\
[2] Coupled ECWAM/IFS with WW3 physics (i.e. different wave & Ardhuin et al., 2010 \\
dissipation and growth parameterizations) & as implemented in \\
[3] Coupled ECWAM/IFS with wave age dependent parameterization & ECWAM. \\
[4] Coupled ECWAM/IFS with empirically-adjusted Charnock 2002 \\
$\begin{array}{l}\text { parameterization } \\
\text { [5] Constant Charnock } 0.018\end{array}$ \\
\hline
\end{tabular}

Table 4. Wind stress parameterizations tested in this study

\begin{tabular}{cccc}
\hline Wind $\left(\mathrm{m} \mathrm{s}^{-1}\right)$ & Mean Charnock & Wind $\left(\mathrm{m} \mathrm{s}^{-1}\right)$ & Mean Charnock \\
\hline 1 & 0.0066 & 23 & 0.0397 \\
2 & 0.0069 & 24 & 0.0413 \\
3 & 0.0079 & 25 & 0.0422 \\
4 & 0.0094 & 26 & 0.0431 \\
5 & 0.0109 & 27 & 0.0443 \\
6 & 0.0120 & 28 & 0.0463 \\
7 & 0.0129 & 29 & 0.0487 \\
8 & 0.0139 & 30 & 0.0491 \\
9 & 0.0150 & 31 & 0.0494
\end{tabular}




\begin{tabular}{cccc}
10 & 0.0164 & 32 & 0.0537 \\
11 & 0.0178 & 33 & 0.0543 \\
12 & 0.0192 & 34 & 0.0586 \\
13 & 0.0205 & 35 & 0.0582 \\
14 & 0.0219 & 36 & 0.0515 \\
15 & 0.0234 & 37 & 0.0518 \\
16 & 0.0249 & 38 & 0.0463 \\
17 & 0.0264 & 39 & 0.0492 \\
18 & 0.0281 & 40 & 0.0490 \\
19 & 0.0300 & 41 & 0.0508 \\
& 0.0322 & 42 & 0.0362 \\
\hline
\end{tabular}

Table A1. Mean Charnock tables for empirically-adjusted Charnock parameterization, based on 2014 year analysis 

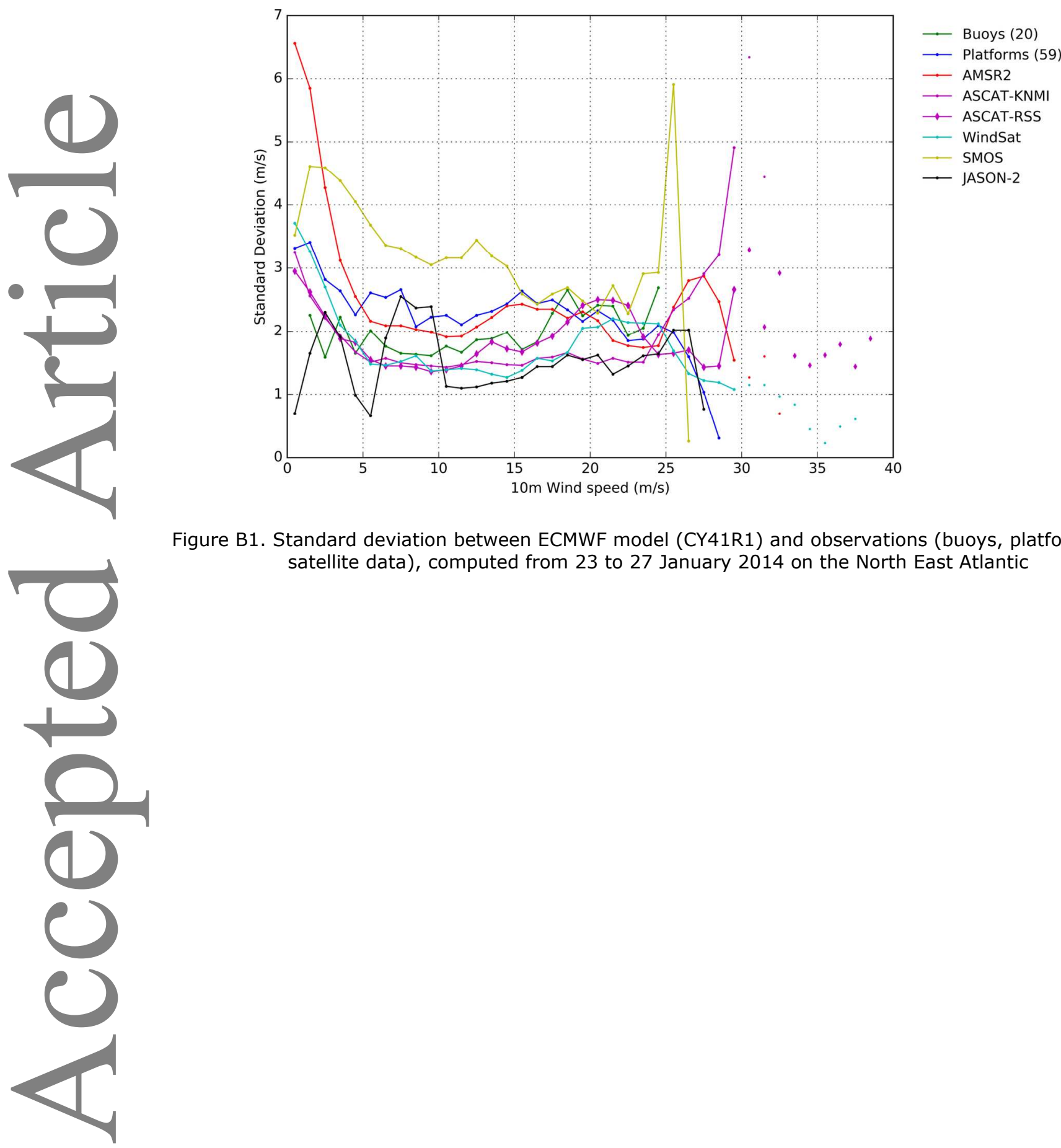

Figure B1. Standard deviation between ECMWF model (CY41R1) and observations (buoys, platforms, and satellite data), computed from 23 to 27 January 2014 on the North East Atlantic 

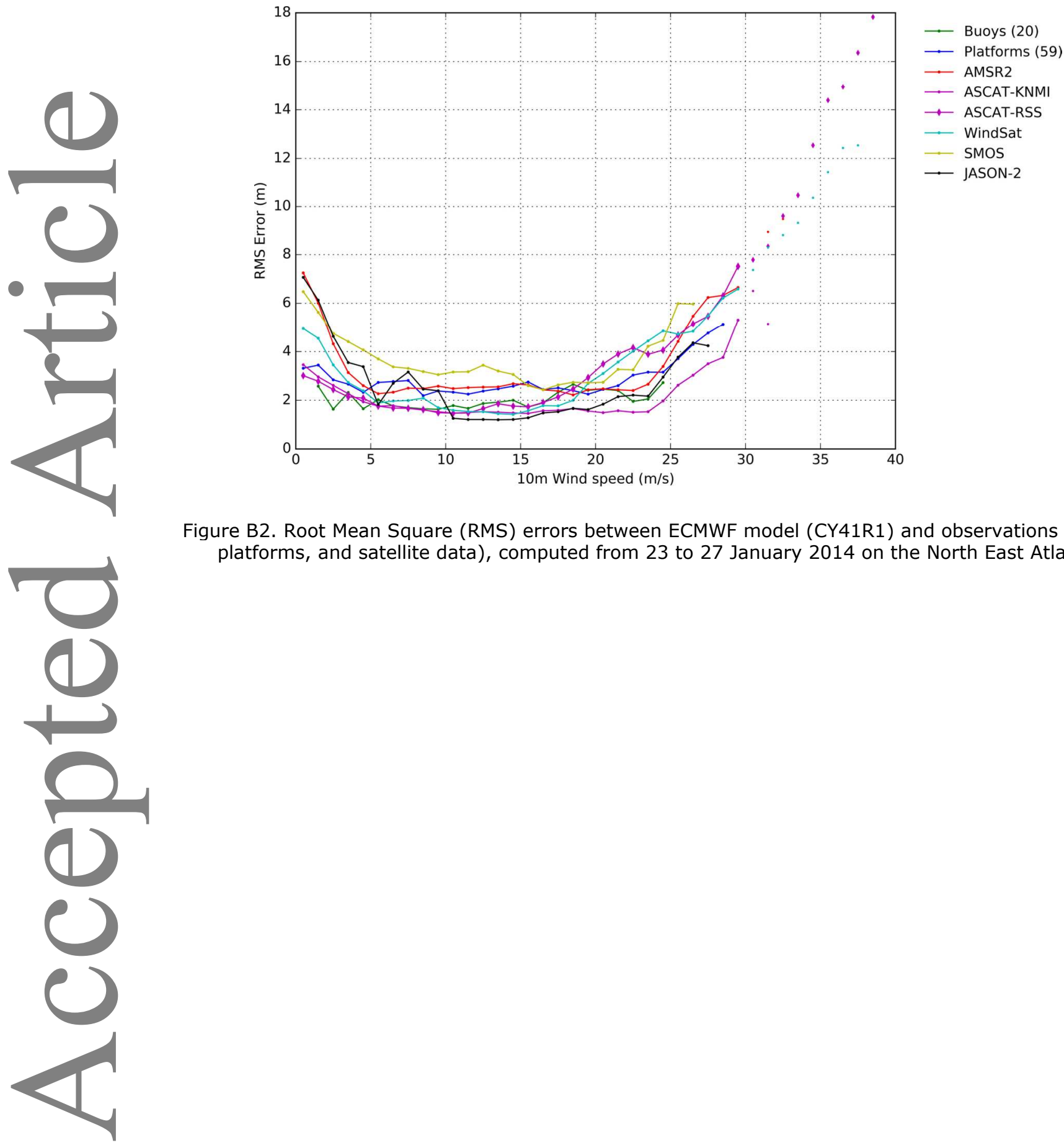

Figure B2. Root Mean Square (RMS) errors between ECMWF model (CY41R1) and observations (buoys, platforms, and satellite data), computed from 23 to 27 January 2014 on the North East Atlantic 